\title{
Spatio-temporal structure of the pentadecadal variability over the North Pacific
}

\author{
Shoshiro Minobe ${ }^{a, b}$,* \\ a Division of Earth and Planetary Sciences, Graduate School of Science, Hokkaido University, \\ Sapporo 060-0810, Japan \\ ${ }^{\mathrm{b}}$ Frontier Research System for Global Change, Tokyo 105-6791, Japan
}

\begin{abstract}
Using a Multi-Taper frequency domain-Singular Value Decomposition (MTM-SVD), a pentadecadal oscillation was detected in the winter-spring sea-level pressure (SLP) field over the North Pacific and surface air-temperature in North America which was significant at the 95\% confidence level. The MTM-SVD captured the different SLP and air-temperature distributions between the winter and spring seasons in a consistent manner. The pentadecadal SLP signature in the spring season is centered nearer the west coast of North America than in the winter season. This zonal displacement is consistent with the prominent springtime pentadecadal airtemperature variability in mid-latitude western North America.

A wavelet analysis of the Pacific Decadal Oscillation Index (PDOI) showed that the regime shifts in the 1920s, 1940s and 1970s involved simultaneous phase reversals of the bidecadal and pentadecadal variations. The two interdecadal variations are synchronized with one another such that a half period of the pentadecadal oscillation (one epoch of an individual regime) corresponds to one and half periods of the bidecadal oscillation. These results are consistent with the wavelet analysis of the North Pacific Index (NPI). Similar resonance between the bidecadal and pentadecadal variations is evident in air-temperatures over Alaska. The bidecadal and pentadecadal signals have different seasonality in these time series, suggesting that although the two interdecadal variations arise from two different physical mechanisms, they interact with each other. The most distinct seasonal difference was observed in mid-latitude western North America, where the bidecadal variation prevails only in the winter season and the pentadecadal variation only in the spring season.

Alaska air-temperatures in the winter and winter-spring of 1999 were the coldest since 1977, as were springtime air-temperatures in mid-latitude western North America, in contrast to the warm anomalies that prevailed in this region during 1977-98. The NPI and PDOI also exhibited an opposite polarity in 1999 to the respective regime mean polarities. These
\end{abstract}

* Tel.: +81-11-706-2644; fax: +81-11-746-2715.

E-mail address: minobe@ep.sci.hokudai.ac.jp (S. Minobe). 
anomalous conditions in winter and spring seasons of 1999 may signify a major regime shift in 1998-1999. In order to verify whether or not a regime shift did occur in 1998-1999, a careful examination of additional data in coming ten or so years will be necessary. (C) 2000 Elsevier Science Ltd. All rights reserved.

\section{Contents}

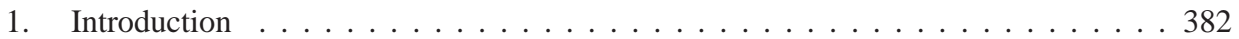

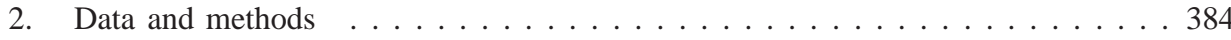

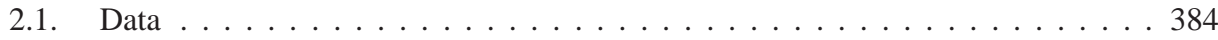

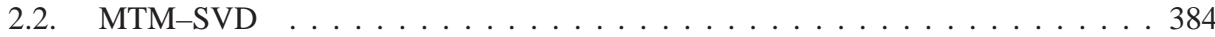

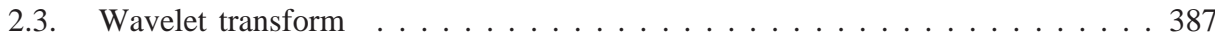

3. Results . . . . . . . . . . . . . . . . . . . . . . . 387

3.1. Winter-spring MTM-SVD . . . . . . . . . . . . . . . . . . 387

3.2. Wavelet analysis of climate indices . . . . . . . . . . . . . . . 392

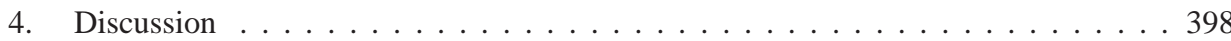

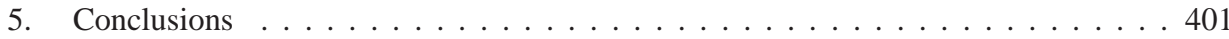

Acknowledgements . . . . . . . . . . . . . . . . . . . . 402

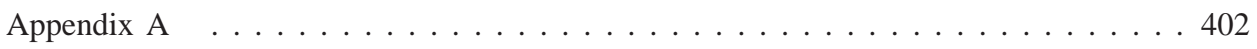

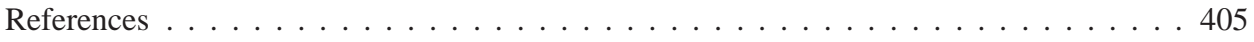

\section{Introduction}

A growing body of literature has revealed that there were climatic regime shifts in the 1920s, 1940s and 1970s which had significant influences on the physical and biological environments over and around the North Pacific. Nitta and Yamada (1989) and Trenberth (1990) reported that in the 1970s the Aleutian low abruptly strengthened. This abrupt change has been referred to as a climatic regime shift. A climatic regime shift is defined as a transition from one climatic state to another within a period substantially shorter than the lengths of the individual epochs of each climate states (e.g., Minobe, 1997). A number of analyses have shown the significant changes occurred in the physical environments in association with the 1970s regime shift (e.g., Graham, 1994; Tanimoto, Iwasaka, Hanawa \& Toba, 1993; Trenberth \& Hurrell, 1994; Miller, Cayan, Barnett, Graham \& Oberhuber, 1994; Miller, Cayan, \& White, 1998; Polovina, Mitchum \& Evans, 1995; Lagerloef, 1995; Nakamura, Lin \& Yamagata, 1997; Zhang \& Levitus, 1997; Schneider, Miller, Alexander \& Deser, 
1999; Tourre, Kushnir \& White, 1999; Zhang \& Liu, 1999; Suga, Kato \& Hanawa (2000)).

Several analyses indicate that similar regime shifts also occurred in the 1920s and 1940s with alternating polarities (Kondo, 1988; Hare \& Francis, 1995; Dettinger \& Cayan, 1995; Zhang, Wallace \& Battisti, 1997; Minobe, 1997; Mantua, Hare, Zhang, Wallace \& Francis, 1997). Mantua et al. (1997) called the low-frequency variability associated with the regime shifts the Pacific (Inter) Decadal Oscillation (PDO). From the point of view of the representative time scale, Minobe (1999) described the lowfrequency variability as a pentadecadal oscillation. All three climatic regime shifts observed in the 20th century have had a significant influence on the marine ecosystems, notably in dramatic changes of several stocks of commercial fish (i.e., Mantua et al., 1997; Kodama, Nagashima \& Izumi, 1995; McGowan, Cayan \& Dorman, 1998; Yasuda, Sugusaki, Watanabe, Minobe \& Oo-zeki, 1999). The pentadecadal variability has also been detected in tree-ring records over the United States and Canada during the 18th and 19th centuries, but with a somewhat longer timescale (from 50-70 years) than the 50 year timescale observed in instrumental data in the present century (Ware, 1995; Minobe, 1997; Shabalova \& Weber, 1999; Ware \& Thomson, 2000).

The three climatic regime shifts are not only important scientific issues intrinsically, but are also important because of their influence on interannual climate variations. Minobe and Mantua (1999) showed that the interannual variability in the wintertime Aleutian low is strong in a regime with a stronger regime-mean Aleutian low, with coherent signatures in the SLP, $500 \mathrm{hPa}$ geopotential height, SST, and wind fields. Gershunov and Barnett (1998) showed that the influence of El Niño and Southern Oscillation (ENSO) on North America is modulated by the regime shifts. Power, Casey, Folland, Colman and Mehta (1999) also indicated that the ENSO influence on Australian rainfall is dependent on the PDO.

An interesting feature of these regime shifts is the rapidity with which the transition from one regime to another occurs. Analyzing a representative SLP time series, the North Pacific Index (NPI) defined by Trenberth and Hurrell (1994), Minobe (1999) explained that all three climatic regime shifts in the 20th century have involved simultaneous phase reversals between the pentadecadal (a period of about 50 years) and bidecadal (a period of about 17 years) oscillations. An epoch of a regime is equivalent to a half period of the pentadecadal variation, and corresponds to one and half periods of the bidecadal variation. In other words, the pentadecadal and bidecadal oscillations are synchronized with a relative period of three. A wavelet analysis of the NPI revealed that the pentadecadal oscillation prevailed both in the winter and spring, but the bidecadal oscillation occurred only in the winter. From these seasonal differences between the bidecadal and pentadecadal variations, it has been inferred that these two climate oscillations are generated by different mechanisms. The bidecadal variability over the North Pacific has been analyzed from various aspects; Royer (1989) first reported the bidecadal variability from an analysis of air and water-temperatures in Alaska. The upper water temperature, or mixed layer depth, was reported to exhibit the bidecadal signal (Lagerloef, 1995; Polovina et al., 1995; Tourre et al., 1999), and bidecadal variations were also detected in 
analyses of basin-scale or global surface temperature and/or SLP (Ghil \& Vautard, 1991; Kawamura, 1994; Polovina et al., 1995; Mann \& Park 1994, 1996; White \& Cayan, 1998; Zhang, Sheng \& Shabbar, 1998; Tourre et al., 1999).

In these previous studies, however, the seasonality and regionality of the pentadecadal variability or regime shifts have not been fully clarified. The pentadecadal signature was evident in the SLP in both the winter and spring seasons (Minobe, 1999), whereas the signature in the air-temperature in mid-latitude western North America is only found in spring (Minobe, 1997). Why there is this different seasonality between the SLP and air-temperature has not yet been explained. In this paper, in order to examine the seasonal and regional dependency more closely, we analyze the SLP and air-temperature by using a MTM-SVD. It is also interesting to examine whether the resonance between the bidecadal and pentadecadal variations shown for the NPI by Minobe (1999) is common to other large scale climate indices, such as the PDO index (PDOI) proposed by Zhang et al. (1997). The PDOI also captures the three climatic regime shifts in the present century (Mantua et al., 1997). So, we have performed a series of the wavelet analyses for the PDOI and area averages for several air-temperatures time series.

\section{Data and methods}

\subsection{Data}

We analyze the following monthly $5^{\circ} \times 5^{\circ}$ gridded SLP and land air-temperature. The SLP data from January 1899 to June 1999 was provided from NCAR, as the updated version of the SLP data of Trenberth and Paolino (1980). The air-temperature data from January 1880 to June 1999 are the gridded version of the Global Historical Climate Network (Vose et al., 1992), the gridding method described by Baker, Eischeid, Karl and Diaz (1995).

As representative climate proxies, the North Pacific Index (NPI) and Pacific Decadal Oscillation Index (PDOI) are analyzed. The NPI was defined by Trenberth and Hurrell (1994) as an area-weighted SLP average over $30-65^{\circ} \mathrm{N}, 160^{\circ} \mathrm{E}-140^{\circ} \mathrm{W}$. It was highly correlated with the leading principal component (PC) of the $500 \mathrm{hPa}$ geopotential height with the associated EOF of a PNA pattern (Trenberth \& Hurrell, 1994), and correlated with the leading PC of the winter SLP anomalies in the North Pacific (Minobe \& Mantua, 1999). The PDOI is the leading PC of monthly SST anomalies in the North Pacific Ocean, polewards of $20^{\circ} \mathrm{N}$ (Zhang et al., 1997; Mantua et al., 1997). The monthly mean global average SST anomalies are removed to separate this pattern of variability from any 'global warming' signal that may be present in the data. Thus, the NPI and PDOI are representative indices for large-scale atmospheric and oceanic changes, respectively, over the North Pacific.

\subsection{MTM-SVD}

We employ a Multi-Taper frequency domain Singular-Value-Decomposition (MTM-SVD) to the SLP and air-temperature data. The first half of the name comes 
from Multi-Taper Method (Thomson, 1982), which is a method to estimate a spectrum using multiple tapers. The multiple tapers, referred to as Slepian tapers, have been chosen to provide independent spectral estimate for an univariate time series. A MTM-SVD is an extension of the original MTM for multi-variate time series analysis.

A MTM-SVD is a single value decomposition of a matrix of multitaper Fourier transforms at each grid; assuming a normalized time series at the $m$ th grid is $x_{n}^{(m)}(n=1, \ldots, N)$, where $n$ is the temporal sample number, and $N$ is the record length. The Fourier transform of the time series using the $k$ th Slepian taper, $T_{n}^{(k)}(=1, \ldots, K)$, is defined as

$$
Y_{k}^{(m)}(f)=\Delta t \sum_{n=1}^{N} T_{n}^{(k)} x_{n}^{(m)} e^{i 2 \pi f n \Delta t}
$$

where $K$ is the number of the tapers and usually chosen to be three for a MTMSVD. The Fourier expansion coefficients, $Y_{k}^{(m)}$, form a following matrix with the size of grid number and taper number at each frequency, $f$,

$$
A(f)=\left[\begin{array}{llll}
w_{1} Y_{1}^{(1)} & w_{1} Y_{2}^{(1)} & \ldots & w_{1} Y_{k}^{(1)} \\
w_{2} Y_{1}^{(2)} & w_{2} Y_{2}^{(2)} & \ldots & w_{2} Y_{k}^{(2)} \\
\vdots & \vdots & \ddots & \vdots \\
w_{M} Y_{1}^{(M)} & w_{M} Y_{2}^{(M)} & \ldots & w_{M} Y_{k}^{(M)}
\end{array}\right]
$$

where $w_{m}(m=1,2, \ldots, m, \ldots, M)$ is the weight propotional to an area represented by the $m$ th grids, and $M$ is the number of grids. The singular value decomposition of the matrix $A$ is written as,

$$
A(f)=\sum_{k=1}^{K} \lambda_{k}(f) \mathbf{u}_{k}(f) \otimes \mathbf{v}_{k}^{*}(f),
$$

where u represents the spatial EOFs, v the spectral EOFs (Mann \& Park, 1994) or spectral modulation (Mann \& Park, 1999), and $\lambda_{k}^{2}$ is the variance explained by the $k$ th spatial and spectral EOFs. A fractional variance, $\lambda_{1}^{2}(f) / \sum_{j=1}^{k} \lambda_{j}^{2}(f)$, gives a measure how dominant the first mode is at each frequency, and is termed as a local fractional variance (LFV) spectrum. For more detailed information for the MTM-SVD, see Mann and Park (1994, 1996, 1999).

The statistical significance of the LFV spectrum is examined by a temporal permutation or shuffling. The permutation destroys any temporal structure longer than one year, but maintains spatial structure (Mann \& Park, 1994, 1996, 1999). The confidence levels at respective frequencies are averaged separately over the inside and outside of a secular band that is at a half band-width from the frequency zero. The

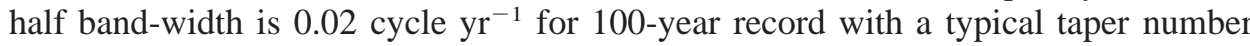
of three. The reason why the confidence levels are averaged inside the secular band isolated from an outside average is to take account of the smaller number of the degrees of freedom at zero frequency than the outside of the secular band, owing 
to vanishing of complex part of the spectrum. As a result, a step of a confidence limit occurs at the boundary of the band. A significance level for a LFV spectrum gives the probability that a single mode can explain observed spatio-temporal structure by chance. We used 1000 surrogate sets of the shuffled data for each MTMSVD analysis.

Although the MTM-SVD is a powerful analysis tool, like other powerful tools, it has weaknesses. The difficulties of interpreting the MTM-SVD results mostly arise when two or more climate signals occur closer than the half band-width in frequency domain. In this case, the MTM-SVD may not be able to distinguish these signals. Thus, a MTM-SVD cannot separate well a 50-year (frequency=0.02 cycle $\mathrm{yr}^{-1}$ ) signal from a trend component (zero frequency) in a 100-year record, and hence the results of the MTM-SVD can be influenced by interference between the two signals. As explained in the Appendix, if there are comparable magnitudes of a secular trend and a 50-year cycle with uncorrelated spatial structures, LFV peak will not occur at 0.02 cycle $\mathrm{yr}^{-1}$ but at a higher frequency (i.e., 0.03 cycle $\mathrm{yr}^{-1}$ ). Even in this case, however, if we reconstruct a representative timeseries for a carrier frequency of 0.03 cycle $\mathrm{yr}^{-1}$, we can have a reconstructed time series that shows a 50-year cycle as shown in the Appendix. Consequently, the peak frequency in the LFV might have an ambiguity of the bandwidth, and hence we need to further examine reconstructed time series.

Previous MTM-SVD analysis of global land air-temperatures (Mann \& Park, 1994) and analysis combined global surface temperatures and northern hemispheric SLPs (Mann \& Park, 1996) failed to capture any significant multidecadal (periods $>25$ years) signal centered in the North Pacific. However, Minobe (1997) and Minobe (1999) demonstrated a pentadecadal variation in the Aleutian low strength over the North Pacific. The lack of the pentadecadal variability in the previous MTM-SVD analyses suggests that the North Pacific pentadecadal signal has been obscured by other climate signals, such as a secular trend and multidecadal oscillations distributed in other regions than the North Pacific. In particular, on the multidecadal timescale, a 70-year oscillation centered in the North Atlantic (Kushnir, 1994; Schlesinger \& Ramankutty, 1994; Mann \& Park, 1994, 1996) may obscure the pentadecadal oscillation in the North Pacific. Therefore, in the present study we apply the MTM-SVD to the North Pacific/North America sector to extract a climate signal limited to the Pacific Sector.

In the present paper, we have performed winter-spring combined MTM-SVD, since a pentadecadal oscillation has been detected in both winter and spring by a wavelet analysis (Minobe, 1999). For the winter-spring combined MTM-SVD, we computed a spectral matrix for the yearly time series for winter and spring at each grid. The number of rows in the matrix for the two-season combined MTM-SVD is double the number of the spatial grids. The resulting LFV spectra and related reconstructions provide information on interannual-to-interdecadal variations with respective dependencies in the winter and spring seasons. 


\subsection{Wavelet transform}

Various climate research applications of wavelet analysis can be found in Weng and Lau (1994), Lau and Weng (1995), and Torrence and Compo (1998). The essential methodology is documented in these references. Here, we briefly summarize the main points of the wavelet transform used in the present paper.

Wavelet transform coefficients of a signal $f(t)$, which varies with time, $t$, are defined as follows:

$$
\tilde{f}\left(t^{\prime}, a\right)=\frac{1}{a^{1 / 2}} \int f(t) \psi *\left(\frac{t-t^{\prime}}{a}\right) \mathrm{d} t,
$$

where $\tilde{f}\left(t^{\prime}, a\right)$ is the wavelet coefficient, $t^{\prime}$ is the translation parameter corresponding to the position of the wavelet, $a$ is the scale dilation parameter that determines the width of the wavelet, and $\psi^{*}$ is the complex conjugate of a mother wavelet, $\psi$. We employ the Morlet wavelet, a commonly used mother wavelet, which is given by a sinusoidal function modulated by a Gaussian envelope, in the following form

$$
\psi(t)=\pi^{-1 / 4} \mathrm{e}^{i w_{0} t} \exp \left(-t^{2} / 2\right),
$$

where $t$ has units of years, and $\omega_{0}$ is a constant that defines the width of the Gaussian envelope of the mother wavelet. In the present study, $\omega_{0}$ is chosen to be 6 (Farge, 1992). In order to avoid 'end effects' before making the wavelet transform, we extended the time series by $30 \%$ at the beginning and end, using an auto-regressive model based on a Maximum Entropy Method of order 30.

The significance of the wavelet amplitude is evaluated by a Monte-Carlo test. In this Monte-Carlo simulation, we generate 10,000 surrogate time series for an observed time series, using a red-noise (AR-1) model with the observed lag-1 correlation coefficient. Each surrogate time series was normalized so that the surrogate variance is identical to the observed variance. The 95 percentile of the absolute wavelet amplitude for the surrogate data provides the $95 \%$ confidence limit. Minobe (1999) showed that the wavelet transform is a useful tool for distinguishing pentadecadal and bidecadal signals in a time series.

\section{Results}

\subsection{Winter-spring MTM-SVD}

Fig. 1 shows the LFV spectra of the winter-spring combined MTM-SVD for the SLP over the North Pacific and western North America. A significant peak on interdecadal timescale occurs at 0.030 cycle $\mathrm{yr}^{-1}$ (33-year period). As noted in the Appendix, the frequency at the LFV peak does not necessarily give a representative timescale, which can be obtained from the reconstruction of a representative time series. The reconstructed time series has about two cycles in a one-hundred year record suggesting that the dominant timescale of the variability is actually about 50 years 


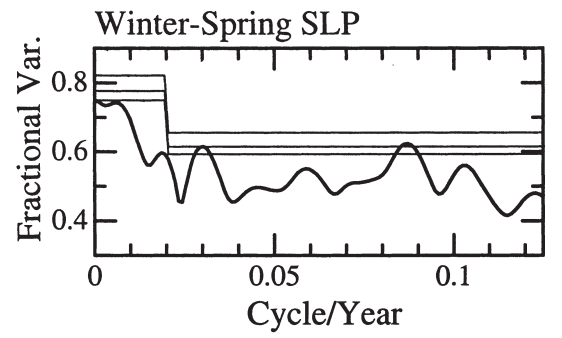

Fig. 1. LFV spectra of the MTM-SVD for combined winter-spring SLP over $20-60^{\circ} \mathrm{N}, 130^{\circ} \mathrm{E}-110^{\circ} \mathrm{W}$. The horizontal lines indicate significance levels at the 99, 95 and $90 \%$ confidence limits.

(Fig. 2), and it exhibits temporal changes that are roughly consistent with the three climatic regime shifts in the present century. Another significant peak occurs at 0.087 cycle $\mathrm{yr}^{-1}$ (11.5-year period) that is consistent with a decadal oscillation detected by previous MTM-SVD analyses (Mann \& Park, 1994, 1996), but we will not discuss this decadal LFV peak further, because our present concern is with the variability on interdecadal timescales.

The reconstructed pattern shown in Fig. 3 reveals a further interesting difference in the spatial patterns between winter and spring. The variability of the wintertime spatial pattern was centered around $170^{\circ} \mathrm{E}$, and its large amplitude region straddles over the most of the Pacific basin zonally, whereas the spring pattern exhibits an eastward shift of the center by about $15^{\circ}$ in longitude, and a larger amplitude tongue extends southeastward from the amplitude maximum. As a result, a steep zonal gradient of the SLP is located around $155^{\circ} \mathrm{W}$ in winter, but just west of the west coast of North America within about $10^{\circ}$ in longitude in spring (Fig. 4). The result of a four-season combined MTM-SVD is the same for the winter and spring seasons, but does not have a large amplitude in the central North Pacific in summer and autumn seasons (not shown).

The difference in seasonality is consistent with the difference maps in the regimemean SLP anomalies between successive epochs (Fig. 5). The difference maps also exhibit a eastward shift in the springtime signature compared with the wintertime one.
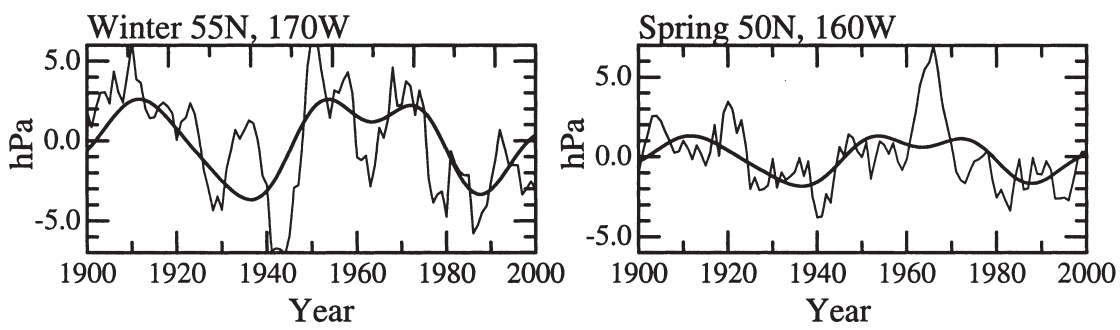

Fig. 2. Reconstructed SLP (thick curve) at $50^{\circ} \mathrm{N}, 170^{\circ} \mathrm{W}$ in winter (left), and at $50^{\circ} \mathrm{N}, 160^{\circ} \mathrm{W}$ in spring (right) at a carrier frequency of 0.030 cycle $\mathrm{yr}^{-1}$. A thin curve shows the observed SLP smoothed by a five-year running mean. The reconstructed variability exhibits an oscillation with about 50-year period. 

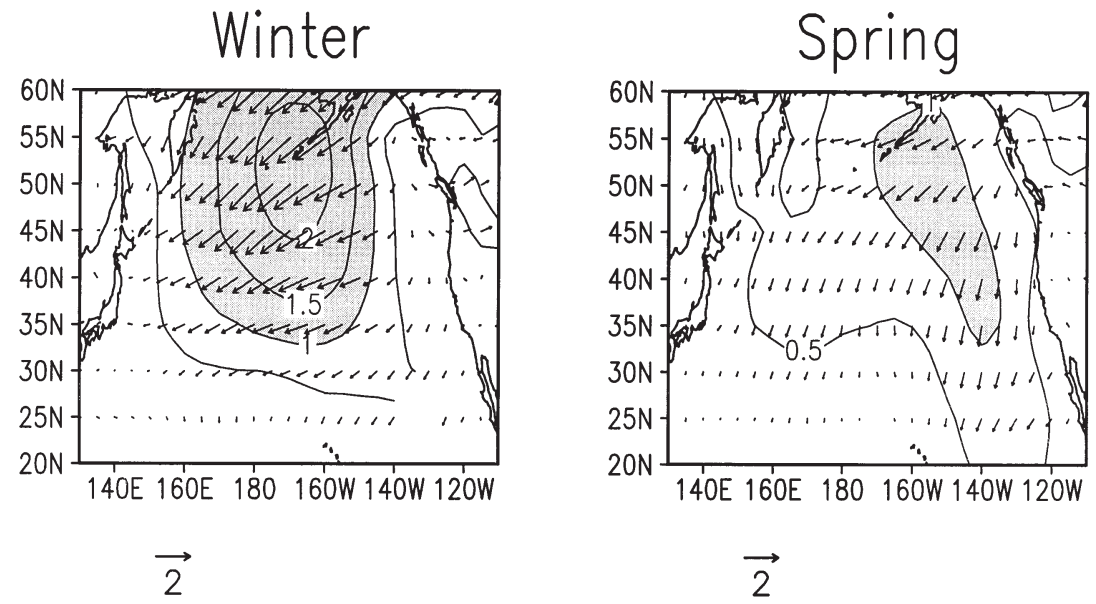

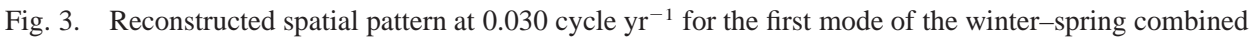
MTM-SVD in arbitrary unit. The contour and arrow length indicate the amplitude, and arrow direction indicates phase (phase delaying in counter clockwise). Contour intervals are 0.5 , and the region where the amplitude is larger than 1 is shaded.
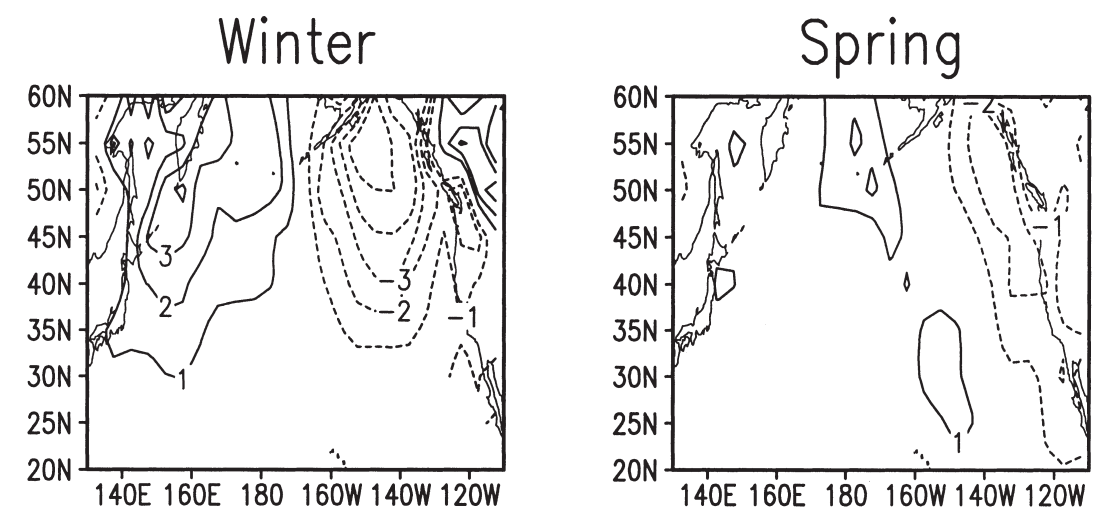

Fig. 4. Zonal derivative of the reconstructed SLP pattern shown in Fig. 3. A projection of the complex amplitude with respect to the phase of the wintertime SLP center $\left(50^{\circ} \mathrm{N}, 170^{\circ} \mathrm{W}\right)$ is shown here.

Another winter-spring combined MTM-SVD analysis was performed for the airtemperature over North America $\left(20-60^{\circ} \mathrm{N}, 180-60^{\circ} \mathrm{W}\right)$. In this case, however, there is no significant LFV peak at a period longer than 8 years. To check for interference between two or more oscillatory signals in a MTM bandwidth, we examined various regional selections for MTM-SVD calculations, and found that there are two multidecadal signals over North America. One is a near 50-year oscillation mainly prevailing in western North America, and the other is a near 70-year oscillation occurring mainly in southeastern North America. The latter signal was associated with the SLP variability over the North Atlantic (e.g., Mann \& Park, 1996). In order to isolate a 

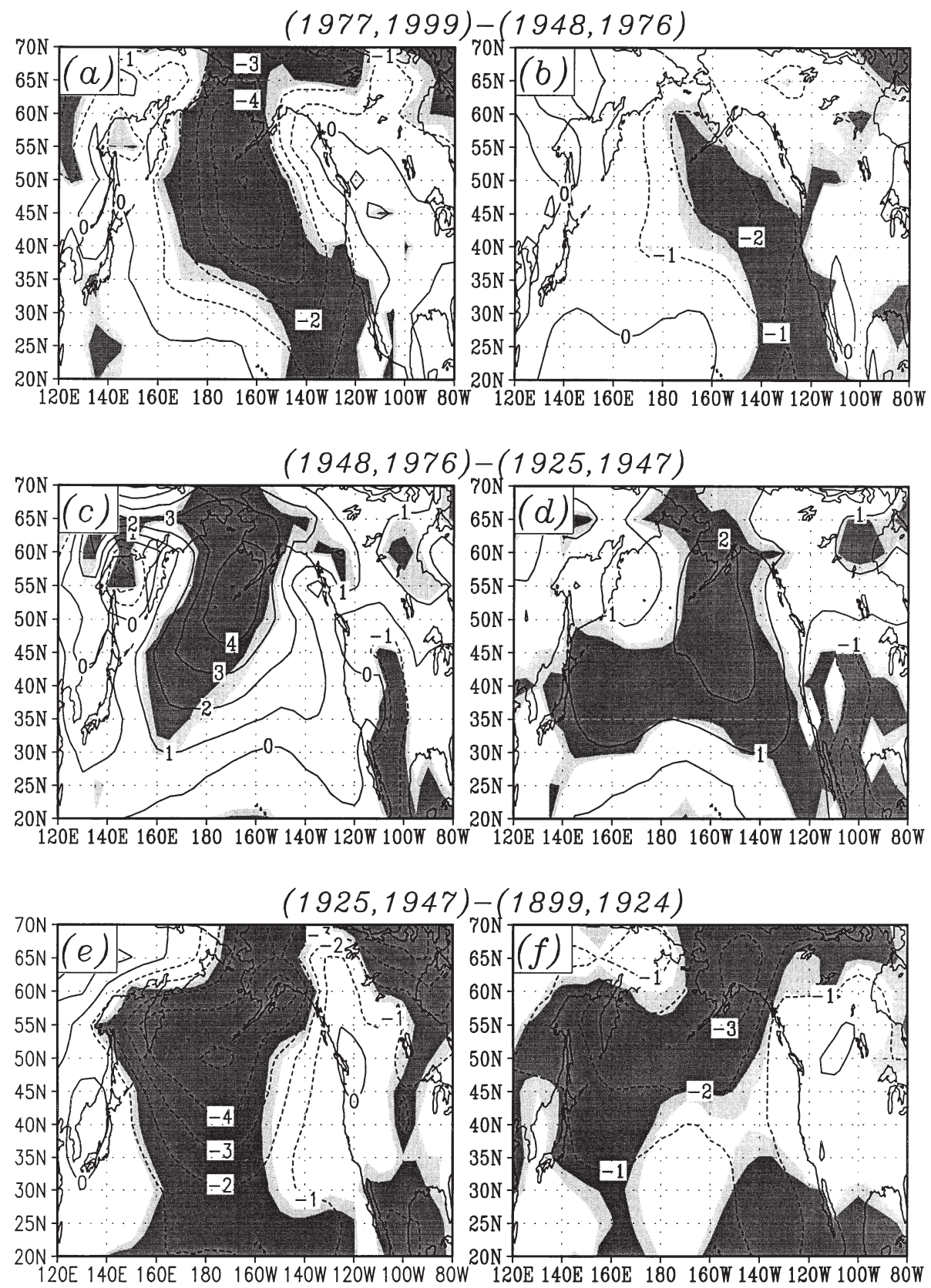


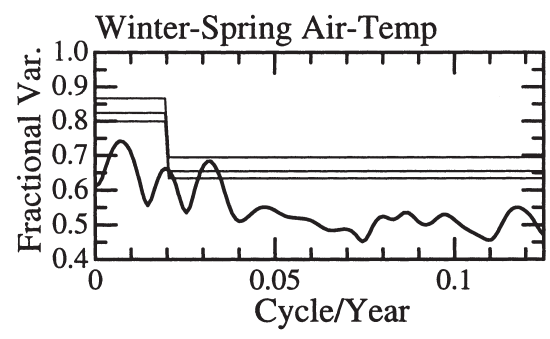

Fig. 6. Same as Fig. 1, but for the winter-spring combined air-temperature over North America, 20$60^{\circ} \mathrm{N}, 180^{\circ}-60^{\circ} \mathrm{W}$. The data south of $40^{\circ} \mathrm{N}$ and east of $100^{\circ} \mathrm{W}$ are not used for the analysis (see text).
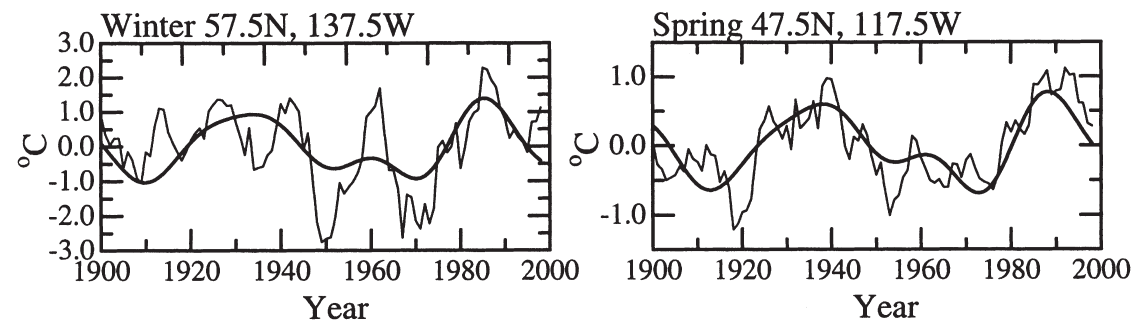

Fig. 7. Same as Fig. 2, but for the reconstructed air-temperature at $57.5^{\circ} \mathrm{N}, 137.5^{\circ} \mathrm{W}$ in the winter (left), and at $47.5^{\circ} \mathrm{N}, 117.5^{\circ} \mathrm{W}$ in the season (right) at a carrier frequency of 0.032 cycle $\mathrm{yr}^{-1}$.

signal potentially relating to the SLP variability over the North Pacific, we removed the air-temperature data south of $40^{\circ} \mathrm{N}$ and east of $100^{\circ} \mathrm{W}$ from the MTM-SVD analysis. The resultant LFV spectra exhibit a significant peak at 0.032 cycle $\mathrm{yr}^{-1}$ (Fig. 6), and once again the reconstructed time series shows a timescale of about 50 years (Fig. 7).

The reconstructed pattern in Fig. 8 shows that this mode has large-amplitude regions in Alaska and western Canada in winter. The corresponding phases are in phase between these regions, and are also in phase with a wide region of mid-latitude western North America in spring. The wintertime phases in North America from $20-50^{\circ} \mathrm{N}$ are not well organized, and may not be a part of a meaningful climate signal. These phase distributions suggest that the climate signal detected by the MTM-SVD are important in Alaska and western Canada in winter, and western midlatitude North America in spring. This is confirmed by the results of the wavelet analysis described below.

The maps of mean air-temperature difference between two epochs further confirm the seasonality of the pentadecadal variability between winter and spring (Fig. 9). In

Fig. 5. SLP difference between two successive periods in winter (left panels) and spring (right panels). The periods are defined as 1977-1999, 1948-1976, 1925-1947 and 1899-1924. The contour indicates the amplitude of the difference and the dens and weak shades indicate the regions where the difference is significant at the $95 \%$ and $90 \%$ confidence limits, respectively, assuming each year is independent. 

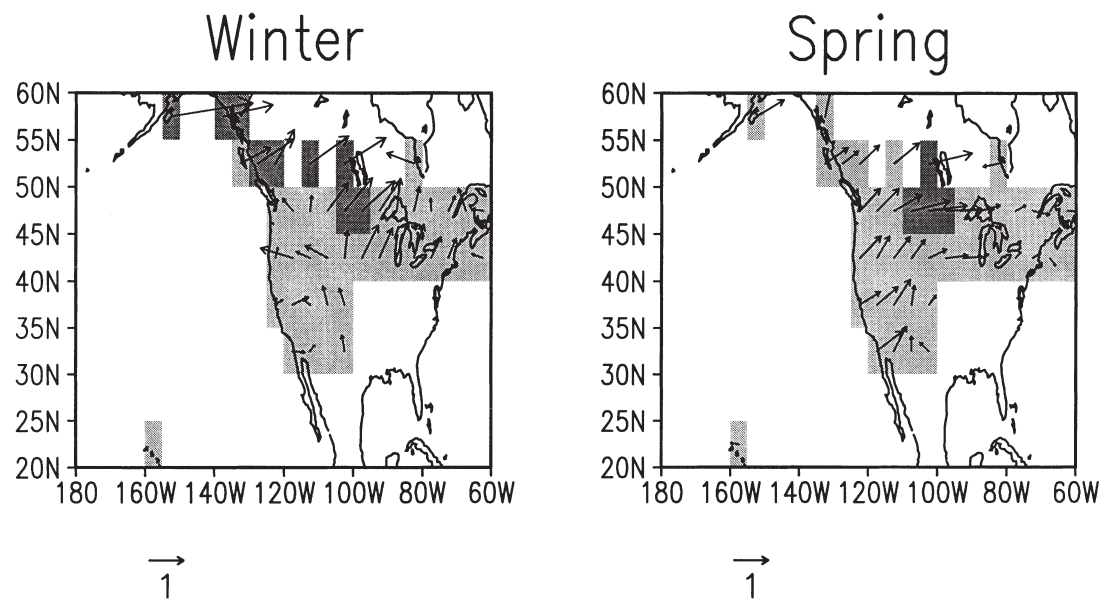

Fig. 8. Reconstructed pattern at 0.032 cycle $\mathrm{yr}^{-1}$ for the first mode of the winter-spring combined airtemperature MTM-SVD. The arrow length indicates the amplitude, and arrow direction indicates the phase (phase delaying in counter clockwise). Dense shade indicates the region where the amplitude is larger than 1 in arbitrary unit, and no shade indicates the grid points that are not used for the MTM-SVD.

the western part of the United States, all the three regime shifts resulted in significant temperature changes during spring, consistent with Minobe (1997). In winter, temperature changes were generally not significant, the exception being the partial warming at the shift in the 1970s, when the SLP difference was located nearer to the west cost of North America than during the earlier two shifts (see Fig. 5). Consequently, the sensitive springtime air-temperature changes of the three regime shifts and the pentadecadal oscillation are consistent with the steep gradient in the SLP quite near the west coast of North America. In Alaska and western Canada, the winter temperature changes were affected by all three of the shifts because of the strong wintertime SLP gradient in that region.

\subsection{Wavelet analysis of climate indices}

In the previous subsection, the seasonality and regionality of the pentadecadal variability were examined by the winter-spring combined MTM-SVD. However, the time-frequency structure was not fully revealed by the MTM-SVD, but can be more suitably expressed by wavelet analysis. Therefore, we now examine the representative time series for the regime shifts using wavelet transform. We focus on how the pentadecadal and bidecadal variations are interrelated. Time series analysed here are the PDOI, NPI and area-averaged air-temperatures.

Fig. 10 shows the NPI time series averaged for winter-spring, winter and spring, respectively. The right panels are updated versions of Fig. 3 of Minobe (1999), which are shown here for an easier comparison with results that will be shown below. The left panel shows that the NPIs smoothed by a 10-80-year filter well fit to the respective non-filtered or 5-year running mean-filtered NPIs. Quasi-simultaneous phase- 


\section{Winter}

\section{Spring}
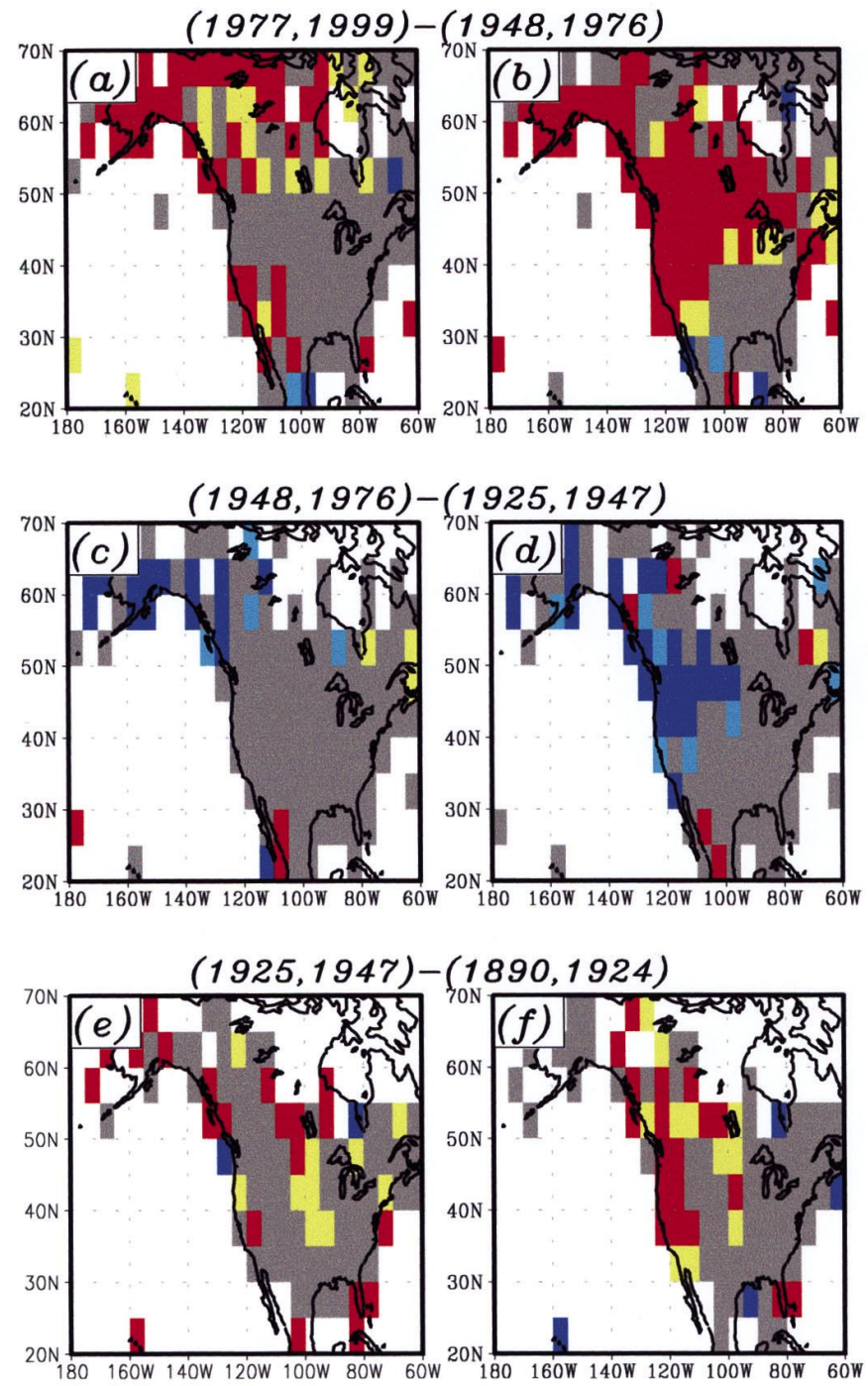

Fig. 9. Same as Fig. 5, but for the air-temperature. Colors indicate the confidence limit of the meantemperature difference, such that a red (yellow) and blue (cyan) colors indicate significant warming and cooling, respectively at the 95(90)\% confidence limit assuming each year is independent. Gray shade indicates that the difference is insignificant at the $90 \%$ confidence limit, and no color indicates a region where only less than 10-year data are available in one epoch and hence the mean difference was not calculated. 


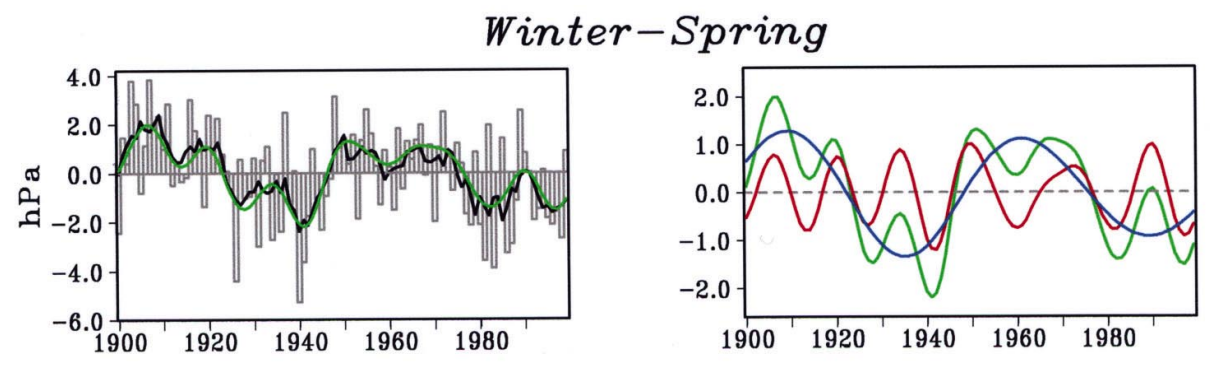

Winter
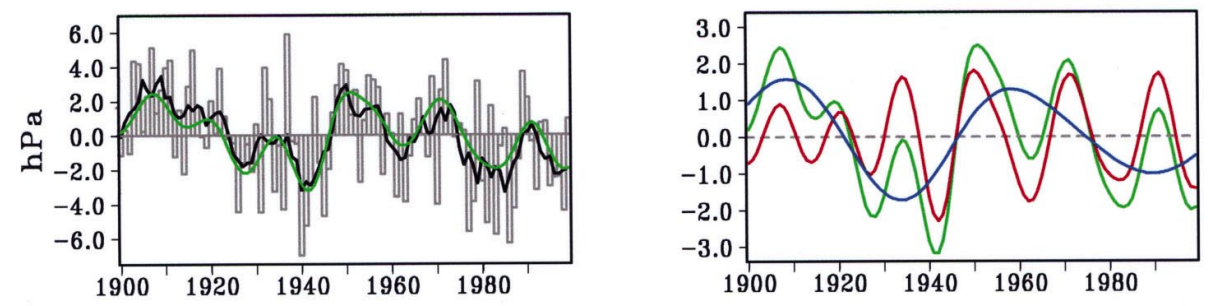

\section{Spring}
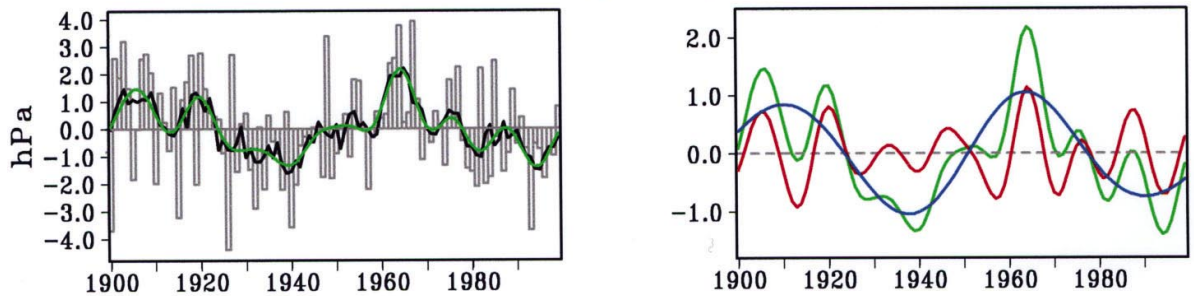

Fig. 10. Filtered NPI (top) in winter-spring, (middle) in winter and (bottom) in spring. In the left panels, the bars indicate the unsmoothed NPI data, black curves indicate the NPI data smoothed by a 5-year running mean, and green curves indicate the 10-80-year band-pass filtered NPI data. In the right panels, the green curves is the 10-80-year band-pass filtered NPI as same as in the left panels, and the red and blue curves indicate the bidecadal (10-30-year) and pentadecadal (30-80-year) filtered NPI data, respectively. The superposition of the bidecadal and pentadecadal filtered NPI is identical to the 10-80-year filtered NPI in each panel. The three cut-off periods for the band-pass filter, 10, 30 and 80 years, are chosen from the wavelet amplitude minima shown in Fig. 12, and a wavelet filter explained in Torrence and Compo (1998) is used.

reversals between the bidecadal and pentadecadal variations are evident in winterspring and winter NPIs for all three regime shifts. No sign of regime shifts is evident in the 1940s and 1970s in the 10-80-year filtered springtime NPI. This lack of any indication of a regime shift results from the phase reversals in the pentadecadal and bidecadal oscillation occurring in opposing directions around 1950, also from the significantly smaller the bidecadal amplitude than the pentadecadal amplitude in the 1970s. Therefore, one can conclude that the simultaneous phase reversals between the pentadecadal and bidecadal variations with comparable amplitude are necessary for a regime shift. 
The quasi-simultaneous phase-reversals between the bidecadal and pentadecadal variations are repeated in the filtered PDOI for the regime shifts of the 1920s, 1940s and 1970s (Fig. 11). The resonant feature in the PDOI is persistent not only in winter and winter-spring average as in the case of the NPI, but also in spring.

Differences in the seasonality of the NPI and PDOI are evident from a visual inspections of the wavelet coefficients shown in Figs. 12 and 13, respectively. As noted by Minobe (1999), the pentadecadal signal in the NPI is evident in both winter and spring, but the bidecadal signal in the NPI is seen only in winter. The bidecadal signal exhibits amplitude and phase increases from 1930-1950. Also the wavelet coefficients of the PDOI exhibit pentadecadal and bidecadal oscillations. The significance level of the pentadecadal oscillation failed to reach the $95 \%$ confidence level throughout the record for winter, and in the early half of the record for in the spring. In contrast, the pentadecadal oscillation in the NPI is significant at the $95 \%$ confidence limit in both seasons throughout the record. Thus, the pentadecadal oscillation is less prominent in the PDOI than in the NPI. Furthermore, in contrast to the

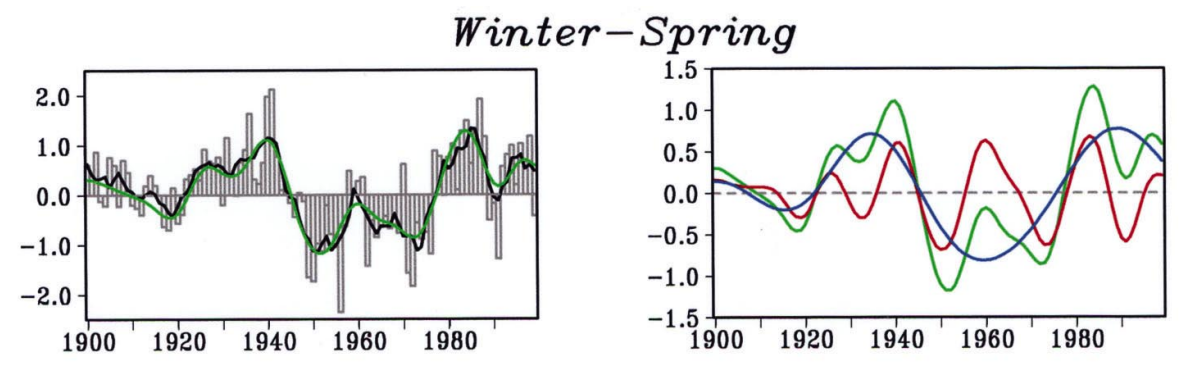

Winter
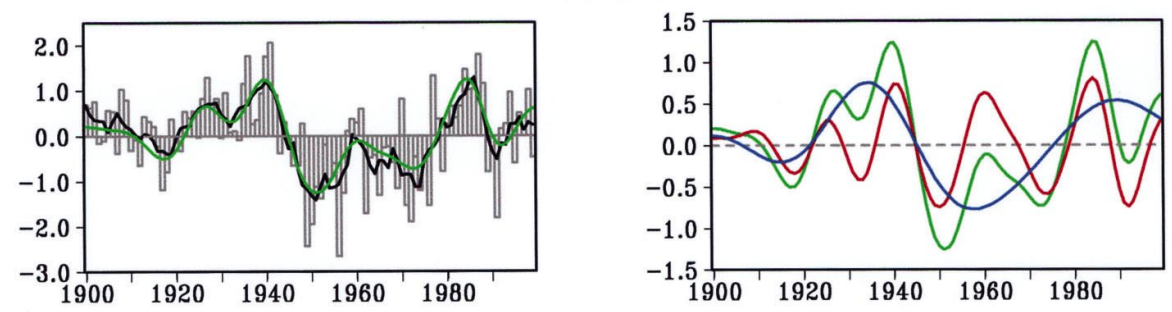

Spring
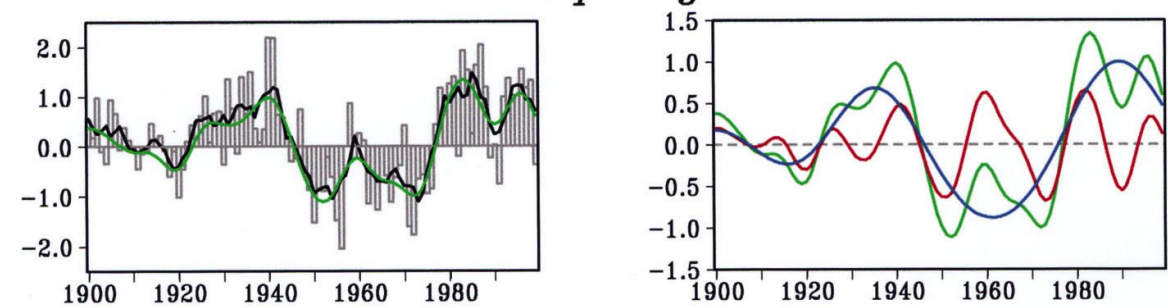

Fig. 11. Same as Fig. 10, but for the PDOI. The three cut-off periods for the band-pass filter, 10, 30 and 100 years, are chosen from the wavelet amplitude minima shown in Fig. 13. 


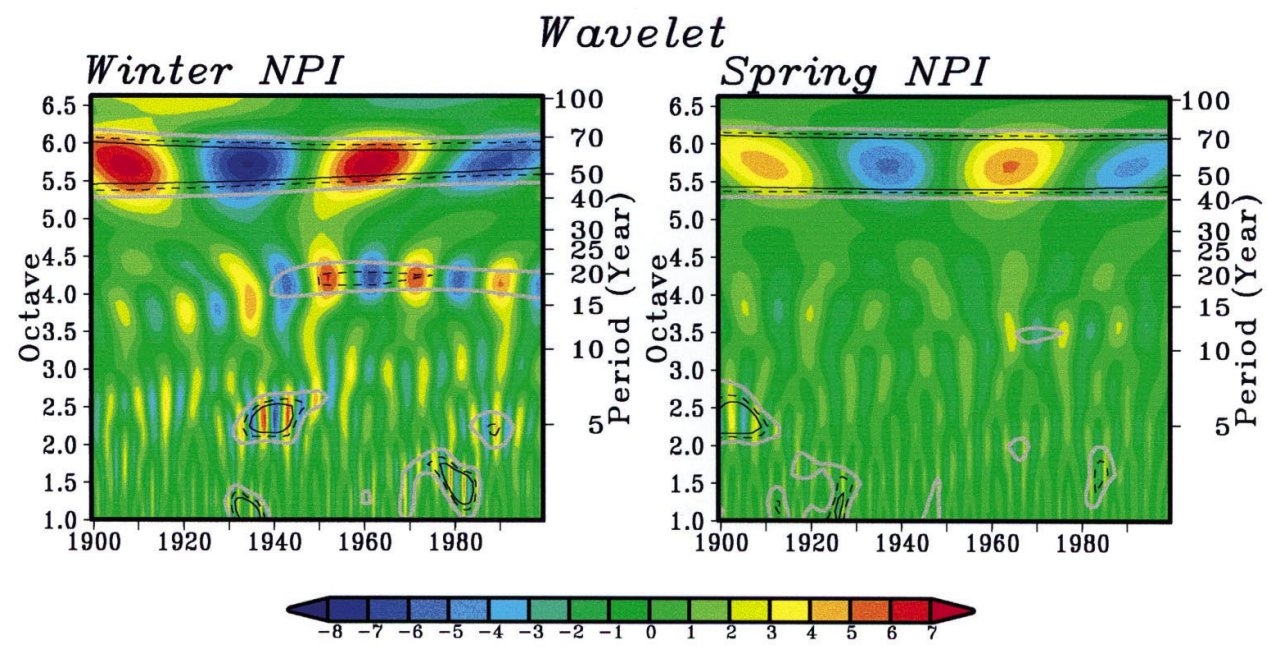

Fig. 12. The NPI wavelet transform coefficient is plotted for (a) winter (December-February) and (b) spring (March-May). The colors indicate the amplitude of the real part of the wavelet coefficient as shown by the color bar in the figure in units of $\mathrm{hPa} \mathrm{yr}^{-1 / 2}$. The black-solid, black-dashed and gray contours indicate that the local wavelet spectrum (which is defined as the square of the absolute wavelet transform coefficient) is significant at the 95, 90 and $80 \%$ confidence levels, respectively. An octave for the left axes is given by $\log _{2}(a)$, where $a$ is a scale dilation parameter in units of years.

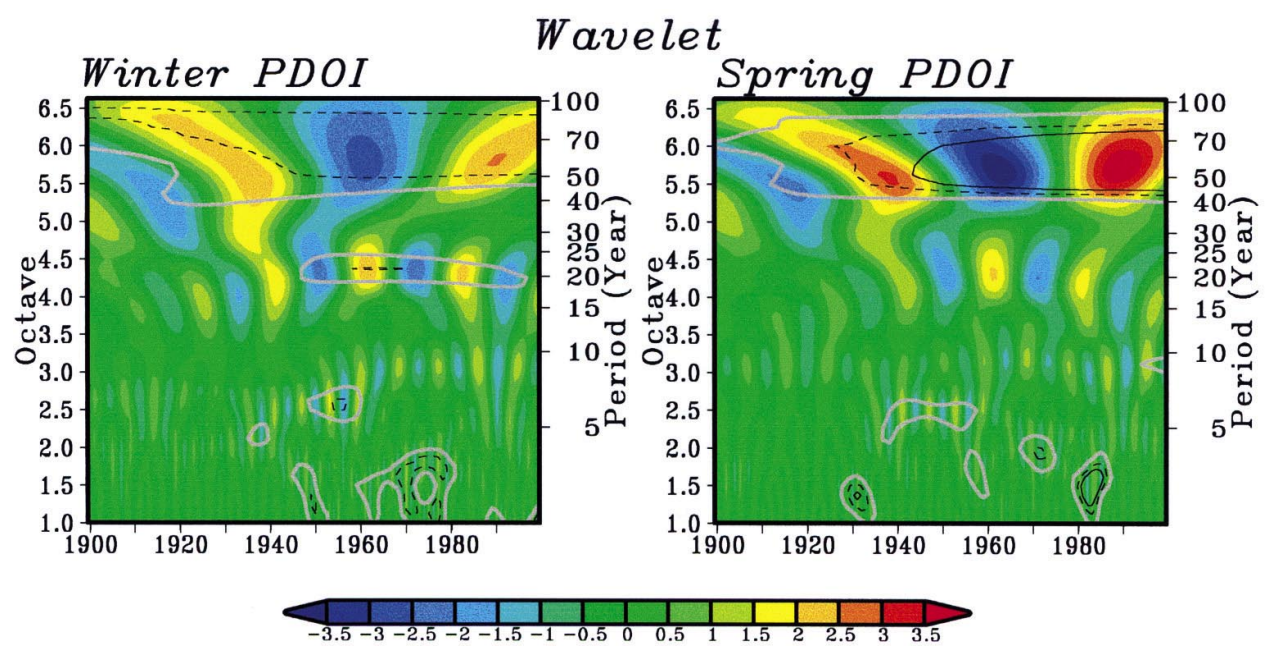

Fig. 13. Same as Fig. 12, but for the PDOI. Units of the wavelet amplitudes is $\mathrm{yr}^{-1 / 2}$. The pentadecadal and bidecadal signals are observed both in winter and spring. However, in winter (spring), the bidecadal (pentadecadal) signal has relatively larger amplitude. 
NPI, the PDOI coefficients indicate stronger pentadecadal oscillations in spring than in winter. Also, the influence of the bidecadal oscillation can be seen in the springtime PDOI. The more energetic springtime pentadecadal and bidecadal amplitudes in the PDOI than in NPI relative to the respective wintertime amplitudes, suggest that there is a lag in the response of the ocean to the atmosphere. In the winter, the amplitude and phase modulation feature in the bidecadal signal is qualitatively the same as in the wintertime NPI.

The wavelet analyses for area-averaged air-temperature time series also provide useful information. The different seasonality of the bidecadal and pentadecadal signals in mid-latitude western North America $\left(30-55^{\circ} \mathrm{N}, 140-110^{\circ} \mathrm{W}\right)$ is evident in the wavelet coefficients shown in Fig. 14. In the winter (spring) season, the bidecadal (pentadecadal) signal is evident, but the pentadecadal (bidecadal) signal is not. The springtime pentadecadal signature is consistent with the result of the MTM-SVD, and air-temperature difference between two epochs shown in Fig. 9 (or Fig. 2 in Minobe, 1997). On the other hand, the wavelet coefficients of the Alaska $\left(55-65^{\circ} \mathrm{N}\right.$, $180-140^{\circ} \mathrm{W}$ ) air-temperature show both the pentadecadal and bidecadal variations (Fig. 15). These two signals are also captured by an eight-order symlet wavelet analysis of Sitka air-temperature from 1829-1996 by Overland, Adams and Mofjeld (2000). The three regime shifts in the wintertime Alaska air-temperature involve again quasi-simultaneous phase reversals of the bidecadal and pentadecadal variations (Fig. 16), while this phase-locking is not apparent in the spring.

The interaction between the bidecadal and pentadecadal variations commonly observed in the NPI, PDOI and Alaska air-temperature has revealed that the three regime shifts in the 1920s, 1940s and 1970s involved quasi-simultaneous phasereversals between the pentadecadal and bidecadal variations in the atmosphere and

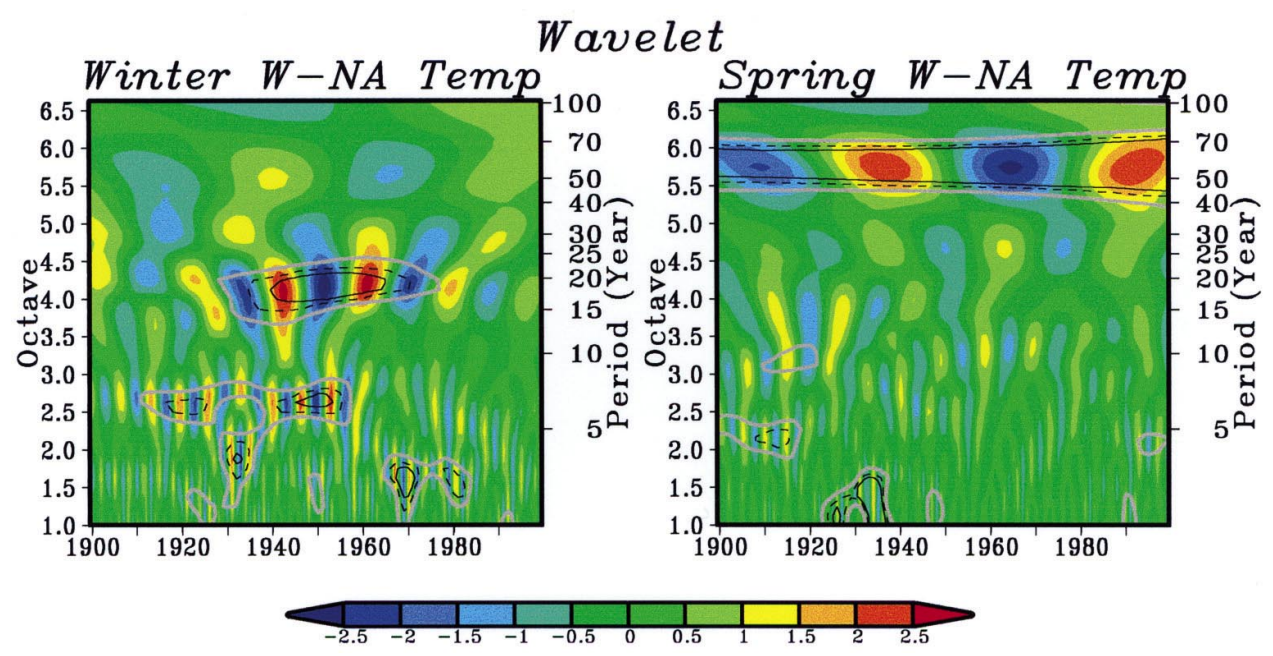

Fig. 14. Same as Fig. 12, but for the air-temperature averaged in mid-latitude western North America $\left(30-55^{\circ} \mathrm{N}, 140-105^{\circ} \mathrm{W}\right)$. Units of the wavelet amplitudes are ${ }^{\circ} \mathrm{C} \mathrm{yr}^{-1 / 2}$. The pentadecadal signal is observed only in spring, and the bidecadal signal is observed only in winter. 


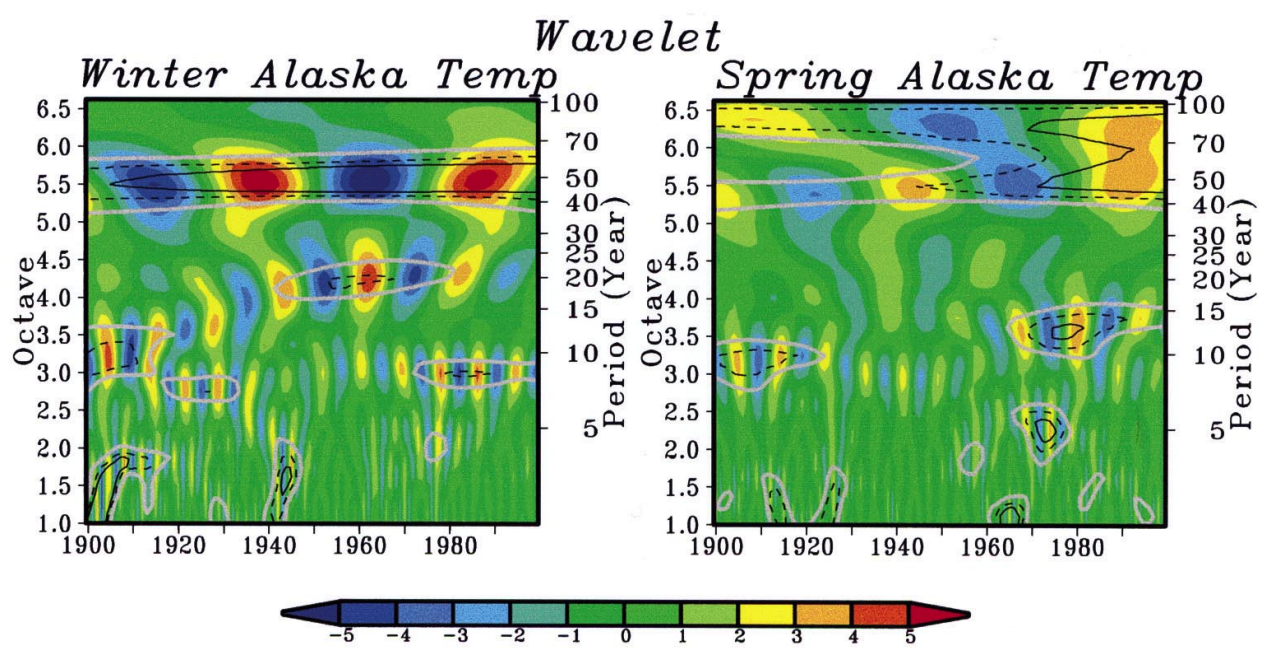

Fig. 15. Same as Fig. 12, but for the air-temperature averaged over Alaska $\left(55-65^{\circ} \mathrm{N}, 180-140^{\circ} \mathrm{W}\right)$. Units of the wavelet amplitudes are ${ }^{\circ} \mathrm{C} \mathrm{yr}^{-1 / 2}$.

ocean. The relative strength of the pentadecadal and bidecadal variations in the representative time series was different between winter and spring; the most distinct manifestation is the air-temperature in mid-latitude western North America, where the pentadecadal variation was evident only in spring, while the bidecadal variation was only seen in winter. These results support the conclusion by Minobe (1999): the climatic regime shifts involve both the pentadecadal and bidecadal oscillations, which resonate with each other at a relative period of three. These two interdecadal variations appear to arise from two different physical mechanisms, but interact with each other. The pentadecadal oscillation provides the basic timescale of a regime length, while the bidecadal oscillation plays an important role in a rapid transition from one regime to the next.

\section{Discussion}

From the point of view of the superposition of the bidecadal and pentadecadal variations, only the three previously noted climatic regime shifts were accompanied by the simultaneous phase reversals of bidecadal and pentadecadal variations in the present century. Several papers documented that a series of atmospheric and oceanographic changes occurred over the North Pacific in 1988/89, and a certain portion of the changes was opposite to the changes which occurred in 1976/77 (Tachibana, Honda \& Takeuchi, 1996; Watanabe \& Nitta, 1999; Overland, Adams \& Bond (1999b)). However, the most of 1988/89 changes reflected only the bidecadal phase reversal, and the phase reversed back again in the early or mid 1990s as shown by the smoothed NPI and PDOI. A similar situation is seen around 1960 in the winter 

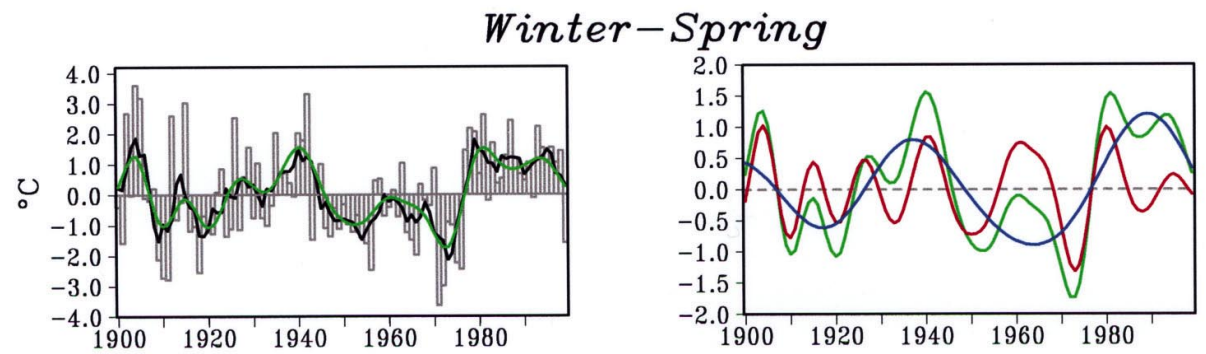

Winter
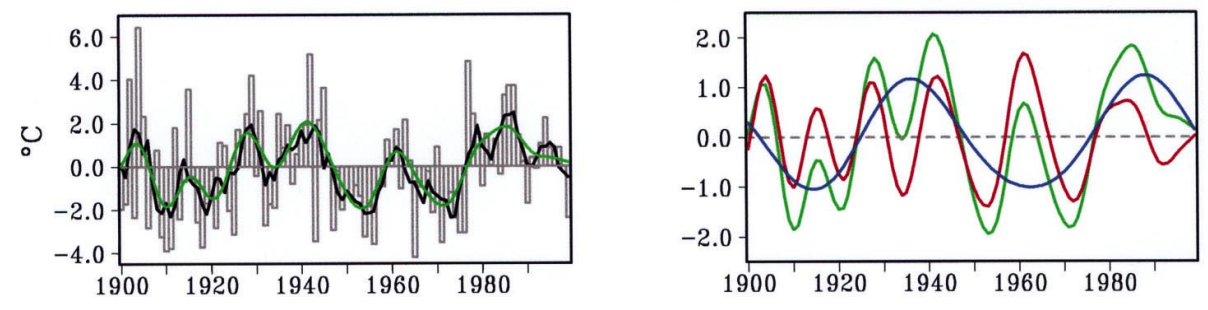

Spring
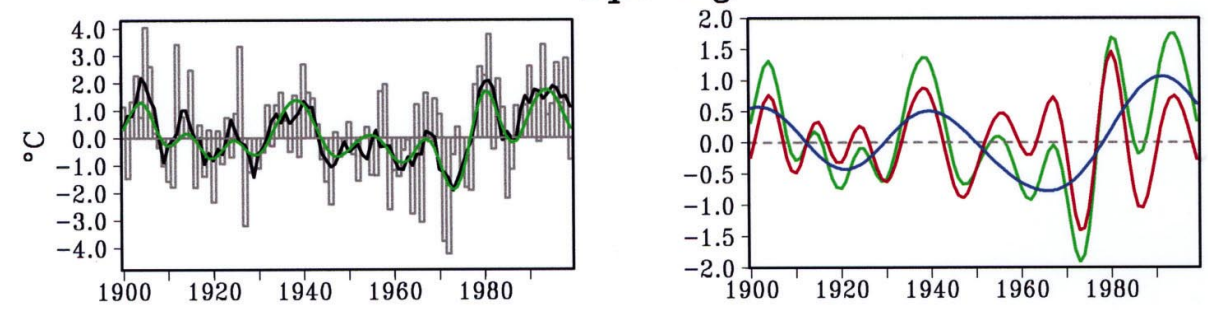

Fig. 16. Same as Fig. 10, but for the air-temperature averaged over Alaska $\left(55-65^{\circ} \mathrm{N}, 180-140^{\circ} \mathrm{W}\right)$.

NPI. Therefore, the 1988/89 change was different from that which occurred in the 1920s, 1940s and 1970s. If we call both types of changes as regime shifts, one may call the shifts in the 1920s, 1940s and 1970s as major regime shifts, and 1988/89 change as a minor regime shift.

The 1988/89 shift can be referred to as minor for the following three reasons. (1) The 1988/89 change is caused only by the bidecadal variability. (2) The regime beginning around 1989 lasted only several years based on the smoothed NPI or PDOI. (3) The polarity reversal around 1990 was observed in the smoothed NPI and PDOI only in winter, but not in spring.

Other minor regime shifts, which mainly reflect the bidecadal oscillation, may have occurred in $1957 / 58,1964 / 65$, and 1994/95 based on the wintertime NPI, and in 1957/58, 1961/62 and 1991/92 based on the wintertime PDOI. The exact year of the minor shifts, however, is likely to be dependent on the relative amplitudes between the bidecadal and pentadecadal oscillations in a time series. Thus, the physical meaning of the exact year of most of the minor shifts may be questionable, 
except for the 1988/89 shift, which is identified as the same year by several independent studies (e.g., Tachibana et al., 1996; Watanabe \& Nitta, 1999; Overland et al., 1999b).

Part of the physical and biological environment changes in the North Pacific may have had a phase reversal in 1988/89 and have conserved its polarity to the present, though this type of change is not apparent in the NPI and PDOI, which exhibited an additional phase reversal in the mid or early 1990s. In an analysis of North Pacific environmental records, Hare and Mantua (2000) showed that this type of change was captured in their third EOF mode for physical parameters, and second EOF mode for biological parameters. Overland, Salo and Adams (1999a) and Hare and Mantua (2000) showed that the cold season (November-March) central strength of the Aleutian low exhibited a change in 1988-89 opposite to that which occurred in the 1970s. They also suggested that the abrupt strengthening of the polar vortex in 1988-89 (Walsh, Chapman \& Shy, 1996; Thompson and Wallace, 1998) may contribute to the observed anomalous change over the North Pacific.

The fact that the change, or minor shift, in 1988/89 did not alter the polarity of the major regime shift does not exclude the possibility that another shift has occurred. Assuming another quasi-simultaneous phase reversal for the next major regime shift, Minobe (1999) suggested that the shift could occur a few years before or after the next bidecadal phase reversal, which is likely to occur between 1999-2000 and 20062007. The difference of a few years between the shift determined via an unfiltered time series and bidecadal phase reversal is due to the effects of a superposed interannual variation. This view suggests that we may already be in the period when the next major regime shift could occur.

It is noteworthy that in the most recent winter-spring in 1999, an outstanding cooling occurred over Alaska (Fig. 16). The winter and winter-spring temperatures over Alaska in 1999 were the lowest since the 1976/77 regime shift, in strong contrast to the regime mean warm anomalies. Also, the spring temperature in mid-latitude western North America was the coldest after 1977 (not shown), and the spring airtemperature in Alaska in 1999 was the coldest in the 1990s.

The NPI and PDOI also exhibited an anomalous situation in 1999 but with a slightly weaker signature than that expressed by Alaska air-temperatures. The NPI showed the largest positive amplitude after 1990, as opposed to the regime mean negative polarity in both winter and spring (Fig. 10). The PDOI showed a negative amplitude opposite to the regime mean positive amplitudes in both winter and spring, with the spring amplitude being the second largest negative amplitude since 1977 (Fig. 11).

Part of the cold anomaly in the 1999 Alaska air-temperature can be associated with the La Niña event which started in June 1998 and was still apparent in February 2000. In order to evaluate how much of the cold anomaly in 1998/99 was explained by the La Niña, we calculated residual air-temperatures, by removing an SOI related air-temperature using a regression relationship between the observed air-temperature and the SOI from 1900 to the present. After removing the La Niña contribution, 1999 is the second coldest year after 1977 over Alaska in both the winter-spring and winter residual temperatures. Consequently, although the La Niña contributed 
to cold anomalies in 1999 over Alaska, a major portion of the observed cold anomaly is likely to originate from other sources of climate variability. We cannot determine confidently whether the anomalous climate in 1999 was the sign of a 1998/99 regime shift, or simply an anomalous year associated with strong interannual fluctuations.

Monitoring the climate indices alone cannot indicate what is occurring on a decadal timescale. For a better understanding of the present state of the decadal climate variability, knowledge of the physical mechanisms for regime shifts is necessary. A prediction model based on the physical understanding would give us more reliable forecast and nowcast for the decadal-multidecadal climate variability over the Pacific Ocean.

\section{Conclusions}

This paper examines aspects of the spatio-temporal structure of the atmospheric and oceanic variability over the North Pacific. The structure of the pentadecadal variability was analyzed by using a winter-spring combined MTM-SVD. The pentadecadal SLP variability in winter is distributed over the entire zonal extent of the Pacific basin, but the springtime SLP pattern is shifted toward the east with the strong zonal SLP gradient only within $10^{\circ}$ longitude from the west coast of North America. This meridional SLP gradient suggests significant anomalies of meridional advection of warmer air from the south onto mid-latitude western North America, and is consistent with this region's pentadecadal air-temperature signature which is observed only in spring, and not in winter.

The wavelet analysis of the PDOI and Alaska air-temperature record supports the hypothesis that the resonant phase reversals between the pentadecadal and bidecadal variations gave rise to the major regime shifts in the 1920s, 1940s and 1970s. A relative seasonality of the pentadecadal and bidecadal signals is noted between winter and spring in the PDOI and air-temperature time series. The significant winter-spring dependency suggests that the pentadecadal and bidecadal signals arose from different physical mechanisms. Therefore, the pentadecadal and bidecadal variations probably have different origins, but interact with each other. Consequently, these results are consistent with those of Minobe (1999).

From the point of view of the resonant interaction between the pentadecadal and bidecadal variations, the climatic regime shifts in the 1920s, 1940s and 1970s differ from those which occurred in 1988/89. The changes observed in 1988/89 are sometimes referred to as evidence for a regime shift. Alternatively, we might label the changes observed in the 1920s, 1940s and 1970s as major regime shifts, and the 1988/89 changes indicative of a minor regime shift, from the dominant variability in the NPI and PDOI. This does not exclude the possibility that another type of regime shift occurred in 1988/89.

The winter and winter-spring air-temperatures in Alaska and spring air-temperature in mid-latitude western North America in 1999 were the coldest observed since 1977, as opposed to the regime mean warm anomalies. Similar, though smaller amplitude polarity changes were noted for the PDOI and NPI in 1999. To know 
whether the 1999 winter marks the beginning of the next major regime shift, or only an anomalous year associated with an interannual fluctuation, we need to continue careful analyses of the observations. Moreover, there is a need for improved methodologies aimed at getting better nowcasts for the regime shifts based on understanding of the physical mechanisms of the shifts. Although an empirical approach to forecast or nowcast the regime shift is quite appealing, the usefulness of such an approach is significantly limited by the small number of the events observed. For example, if we can assume that the next regime shift occurs as a simultaneous phase reversal between the bidecadal and pentadecadal variations, as described by Minobe (1999), we can predict the next regime shift with an ambiguity of about ten years. However, we cannot evaluate the accuracy of this assumption, there having been only three realizations of major regime shifts in the past century. In order to understand and to predict future regime shifts, we need to understand their physical mechanisms. Although several mechanisms have been proposed as sources for the bidecadal timescale (e.g., Latif \& Barnett 1994, 1996; Jin, 1997; Gu \& Philander, 1997; White \& Cayan, 1998; Weng \& Neelin, 1999; Tallery, 1999), a plausible hypothesis has not yet been presented for the pentadecadal variability. The author hopes that there will be significant progress in understanding the mechanisms responsible for the pentadecadal variability and its interaction with the bidecadal variability in near future.

\section{Acknowledgements}

I thank Y. Kushnir, M. Scheledinger, and M. Shabalova for invaluable discussions, R.-H. Zhang, N. Schneider, L. D. Talley and D.M. Ware for preprints and reprints, N. Mantua for Pacific Decadal Oscillation Index, M.E. Mann for source code of the MTM-SVD. Insightful advises by N. Mantua and an anonymous reviewer are helpful to improve the present paper. Some figures are produced with the GrADS developed by B. Doty. This study is supported by grants from the Japanese Ministry of Education, Culture and Science.

\section{Appendix A}

As with any statistical tool for climate signal detection, the MTM-SVD must be used carefully. Most difficulties in interpreting the MTM-SVD results are associated with two or more signals, more closely spaced than a half-band width in the frequency domain. The half-band width for a 100-year record is 0.02 cycle $\mathrm{yr}^{-1}$ with the use of three tapers. Unfortunately, such a situation is often encountered in climate studies. Therefore, the behavior of the MTM-SVD results is described here, when two multidecadal variations interfere with each other.

We conducted a series of the MTM-SVD analyses for test data of a following form,

$$
f(x, y, t)=S_{1}(x, y, t)+S_{2}(x, y, t)+\varepsilon(x, y, t)
$$


where $x, y$ are the spatial coordinate, $t$ the time, $f$ is the observed value, $S_{1}$ and $S_{2}$ are two signal components, and $\varepsilon$ is the white noise. The first signal is a sinusoidal oscillation with a frequency of 0.02 (period of 50) in nondimensional unit, as given by

$$
S_{1}(x, y, t)=X_{1}(x, y) \sin (2 \pi t / 50),
$$

where $X_{1}(x, y)$ is a spatial pattern of a Gaussian form shown in Fig. 17a. The number of spatial grids is five and five in the $x$ and $y$ directions, respectively. The temporal development of the second signal is a linear trend or a sinusoidal oscillation with a different frequency $\left(f_{2}=0.03,0.05\right.$ and 0.07$)$, and the spatial pattern of the second signal is a seesaw-like pattern (Fig. 17b), which is orthogonal to the spatial pattern of the first signal component. The energy (sum of the variance at respective grid points) of the first signal component is set to be identical to the energy of the second signal component, and the white noise energy is taken to be the same as the energy of the total signal, which are superposition of the two signal components. The LFV spectra of four experiments are shown in Fig. 18.

For panels (a) and (b) of the Fig. 18, the difference between two true signals in the frequency domain is less than, or equal to, the half-band width. In this case, the LFV amplitude at the true peak frequency is weakened due to the interference of two oscillatory components. The LFV amplitude associated with one signal component is not influenced by the other signal component outside a half band-width from the latter. Consequently, the LFV peak frequencies shift outside each other than the true peak frequencies. In the panel (c), the true peaks are separated more than the half band width, and hence the LFV peaks at true peak frequencies are not affected compared with the panels (a) and (b). However, even in this case, interference between two peaks caused asymmetric shape of the large LFV amplitude, resulting in outside shifts of the the LFV peak frequencies. In the panel (d), the true peaks separated more than the full band width (0.04 in frequency). Therefore, in this case,
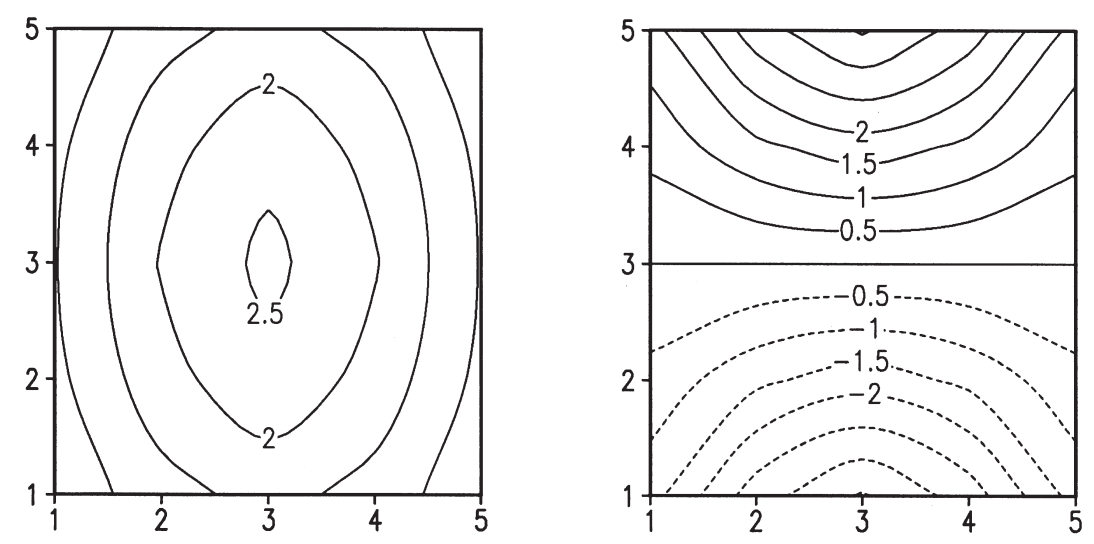

Fig. 17. Spatial pattern used for the test of the MTM-SVD. The signal component of the test data consist of the sum of two components with these uncorrelated spatial patterns (see text of Appendix). 

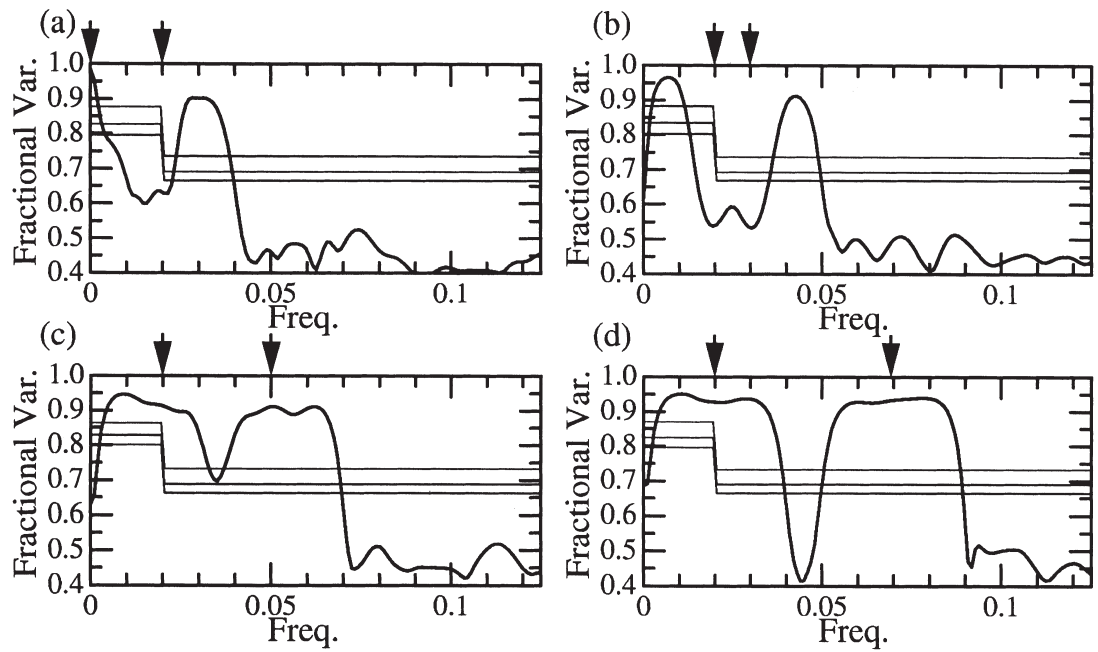

Fig. 18. LFV spectra for the data consists of two signal components and white noise. For all panels, one signal is sinusoidal oscillation with a frequency of 0.02 with the Gaussian spatial pattern shown in the left panel of Fig. 18. The other signal is (a) a linear-trend, or oscillations with a frequency of 0.03 (b), 0.05 (c) and 0.07 (d) with the spatial pattern shown in the right panel in Fig. 17. The half and full band width are 0.02 and 0.04 in frequency, respectively.

the two oscillations do not affect each other. The resultant LFV shape is qualitatively the same as that associated with single periodic oscillation (not shown).

As a summary, when the frequencies of the two signals are closer than the full band-width with uncorrelated spatial patterns, the peak frequencies of the LFV spectra tend to separated more than the true peaks. In particular, the frequency distance between the true peaks is smaller than the half band-width, the interference between two oscillations cause significantly low LFV values at respective true peak frequencies.

In the case where the interference between two oscillations cannot be ignored, the reconstructed time series can give us more accurate information about the dominant timescale. Fig. 19 shows time series reconstructed at the center of the spatial domain at a carrier frequency corresponding to the apparent LFV peak $(0.03,0.007,0.01$ and 0.02 for panels (a)-(d), respectively). Regardless of the different carrier frequencies, the oscillation period of 50 in the non-dimensional unit is evident in all reconstructed time series. Unfortunately, we cannot know whether or not significant interference occurs solely from the LFV spectral distribution, and hence we need to further examine reconstructed time series in order to understand the dominant timescale of the phenomenon.

As illustrated in this Appendix, new methods, such as MTM-SVD and wavelet analysis, might have some weakness which has not been fully documented. Therefore, for a better understanding of the decadal-multidecadal climate variability, it is desirable to address the capability of different analysis methods in detecting a low frequency signal from a relatively short record. 
(a)

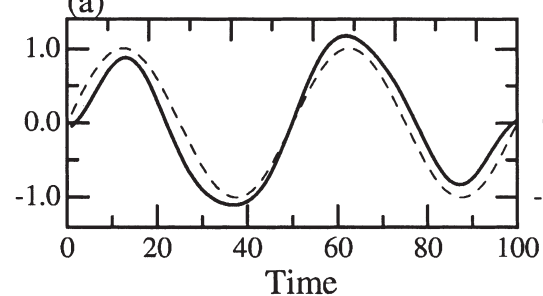

(c)

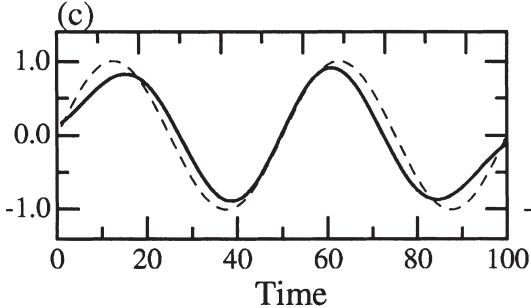

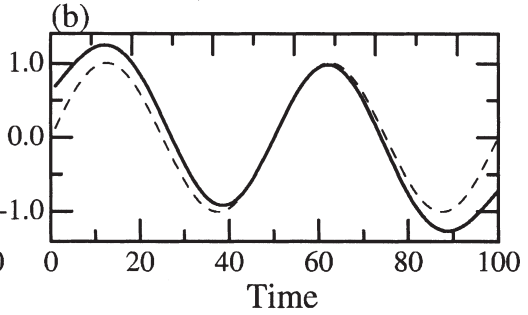

(d)

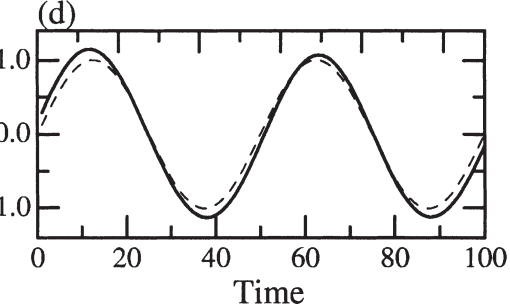

Fig. 19. Reconstructed time series (thick solid curve) and original signal time series (thin dashed curve) at the center of the spatial domain. The carrier frequency used for the each reconstruction is chosen to be the frequency of the LFV peak in Fig. 18, namely, 0.03 (a), 0.007 (b), 0.01 (c) and 0.02 (d). In spite of the different carrier frequencies, all the reconstructed time series exhibit similar oscillations with a period of about 50 in nondimensional unit.

\section{References}

Baker, C. B., Eischeid, J. K., Karl, T. R., \& Diaz, H. F. (1995). The quality control of long-term climatological data using objective data analysis. Preprints of AMS Ninth Conference on Applied Climatology, Dallas, TX, January 15-20.

Dettinger, M. D., \& Cayan, D. R. (1995). Large-scale atmospheric forcing of recent trends toward early Snowmelt Runoff in California. Journal of Climate, 8, 606-623.

Farge, M. (1992). Wavelet transforms and their applications to turbulence. Annual Review of Fluid Mechanics, 24, 395-457.

Gershunov, A., \& Barnett, T. P. (1998). Interdecadal Modulation of ENSO Teleconnections. Bulletin of the American Meteorological Society, 79, 2715-2726.

Ghil, M., \& Vautard, R. (1991). Interdecadal oscillations and the warming trend in global temperature time series. Nature, London, 350, 324-327.

Graham, N. E. (1994). Decadal scale variability in the 1970s and 1980s: observations and model results. Climate Dynamics, 10, 135-162.

Gu, D. F., \& Philander, S. G. H. (1997). Interdecadal climate fluctuations that depend on exchanges between the tropics and extratropics. Science, 275, 805-807.

Hare, S. R., \& Francis, R. C. (1995). Climate change and salmon production in the Northeast Pacific Ocean. In R. J. Beamish, Ocean climate and northern fish populations. Canadian Special Publication of Fisheries and Aquatic Sciences (pp. 357-372).

Hare, S. R., \& Mantua, N. J. (2000). Empirical evidence for North Pacific regime shifts in 1977 and 1989. Progress in Oceanography, 47, 103-145.

Jin, F.-F. (1997). A theory of interdecadal climate variability of the North Pacific ocean-atmosphere system. Journal of Climate, 10, 324-338.

Kawamura, R. (1994). A rotated EOF analysis of global sea surface temperature variability with interannual and interdecadal scales. Journal of Physical Oceanography, 24, 707-715.

Kodama, J., Nagashima, H., \& Izumi, Y. (1995). Long-term variations in the 'mongoku herring' clupea 
pallasi valenciennes resources in relation to the ocean environments in the waters off sanrikua and Joban. Bulletin of Miyagi Prefecture Fishery Research Division Center, 14, 17-36 (in Japanese).

Kondo, J. (1988). Volcanic eruptions, cool summers and famines in the northeastern part of Japan. Journal of Climate, 1, 775-788.

Kushnir, Y. (1994). Interdecadal variations in North Atlantic sea surface temperature and associated atmospheric conditions. Journal of Climate, 7, 141-157.

Lagerloef, G. S. E. (1995). Interdecadal variations in the Alaska gyre. Journal of Physical Oceanography, $25,2242-2258$.

Latif, M., \& Barnett, T. P. (1994). Causes of decadal climate variability over the North Pacific and North America. Science, 266, 634-637.

Latif, M., \& Barnett, T. P. (1996). Decadal climate variability over the North Pacific and North America: dynamics and predictability. Journal of Climate, 9, 2407-2423.

Lau, K.-M., \& Weng, H. (1995). Climate signal detection using wavelet transform: how to make a time series sing. Bulletin of the American Meteorological Society, 76, 2391-2402.

Mann, M. E., \& Park, J. (1994). Global-scale modes of surface temperature variability on interannual to century timescale. Journal of Geophysical Research, 99, 25819-25833.

Mann, M. E., \& Park, J. (1996). Joint spatiotemporal modes of surface temperature and sea level pressure variability in the Northern Hemisphere during the last century. Journal of Climate, 9, 2137-2162.

Mann, M. E., \& Park, J. (1999). Oscillatory spatiotemporal signal detection in climate studies: a multipletaper spectral domain approach. Advances in Geophysics, 41, 1-131.

Mantua, N. J., Hare, S. R., Zhang, Y., Wallace, J. M., \& Francis, R. C. (1997). A Pacific interdecadal climate oscillation with impacts on salmon production. Bulletin of American Meteorological Society, 76, 1069-1079.

McGowan, J. A., Cayan, D. R., \& Dorman, L. M. (1998). Climate-ocean variability and ecosystem response in the Northeast Pacific. Science, 281, 210-217.

Miller, A. J., Cayan, D. R., Barnett, T. P., Graham, N. E., \& Oberhuber, J. M. (1994). The 1976-1977 climate shift of the Pacific Ocean. Oceanography, 7, 21-26.

Miller, A. J., Cayan, D. R., \& White, W. B. (1998). A westward-intensified decadal change in the North Pacific thermocline and gyre-scale circulation. Journal of Climate, 11, 3112-3127.

Minobe, S. (1997). A 50-70 year climatic oscillation over the North Pacific and North America. Geophysical Research Letters, 24, 683-686.

Minobe, S. (1999). Resonance in bidecadal and pentadecadal climate oscillations over the North Pacific: role in climatic regime shifts. Geophysical Research Letters, 26, 855-858.

Minobe, S., \& Mantua, N. (1999). Interdecadal modulation of interannual atmospheric and oceanic variability over the North Pacific. Progress in Oceanography, 43, 163-192.

Nakamura, H., Lin, G., \& Yamagata, T. (1997). Decadal climate variability in the North Pacific during the recent decades. Bulletin of American Meteorological Society, 98, 2215-2225.

Nitta, T., \& Yamada, S. (1989). Recent warming of tropical sea surface temperature and its relationship to the Northern Hemisphere circulation. Journal of Meteorological Society of Japan, 67, 375-383.

Overland, J. E., Salo, S., \& Adams, J. M. (1999a). Salinity signature of the Pacific Decadal Oscillation. Geophysical Research Letters, 26, 1337-1340.

Overland, J. E., Adams, J. M., \& Bond, M. A. (1999b). Decadal variability of the Aleutian low and its relation to high-latitude circulation. Journal of Climate, 12, 1542-1548.

Overland, J. E., Adams, J. M., \& Mofjeld, H. J. (2000). Chaos in the North Pacific: spatial modes and temporal irregularity. Progress in Oceanography, 47, 337-354.

Polovina, J. J., Mitchum, G. T., \& Evans, G. T. (1995). Decadal and basin-scale variation in mixed layer depth and the impact on biological production in the Central and North Pacific, 1960-88. Deep-Sea Research, 42, 1701-1716.

Power, S., Casey, T., Folland, C., Colman, A., \& Mehta, V. (1999). Inter-decadal modulation of the impact of ENSO on Australia. Climate Dynamics, 15, 319-324.

Royer, T. C. (1989). Upper ocean temperature variability in the northeast Pacific: is it an indicator of global warming? Journal of Geophysical Research, 94, 18175-18183.

Schlesinger, M. E., \& Ramankutty, N. (1994). An oscillation in the global climate system of period 6570 years. Nature, London, 367, 723-726. 
Schneider, N., Miller, A. J., Alexander, M. A., \& Deser, C. (1999). Subduction of decadal North Pacific temperature anomalies: observations and dynamics. Journal of Physical Oceanography, 29, 10561070 .

Shabalova, M. V., \& Weber, S. L. (1999). Patterns of temperature variability on mutidecadal to centennial timescales. Journal of Geophysical Research, 104, 31023-31041.

Suga, T., Kato, A., \& Hanawa, K. (2000). North Pacific Tropical Water: its climatology and temporal changes associated with the climate regime shift in the 1970s. Progress in Oceanography, 47, $223-256$.

Tachibana, Y., Honda, M., \& Takeuchi, K. (1996). The abrupt decrease of the sea ice over the southern part of the Sea of Okhotsk in 1989 and its relation to the recent weakening of the Aleutian low. Journal of the Meteorological Society of Japan, 74, 579-584.

Tanimoto, Y., Iwasaka, N., Hanawa, K., \& Toba, Y. (1993). Characteristic variation of sea surface temperature with multiple time scale in the North Pacific. Journal of Climate, 6, 1153-1160.

Tallery, L. D. (1999). Simple coupled mid-latitude climate models. Journal of Physical Oceanography, 29, 2016-2037.

Thomson, D. J. (1982). Spectrum estimation and harmonic analysis. Proc. IEEE, 70, 1055-1096.

Thompson, D. W. J., \& Wallace, J. M. (1998). The Arctic Oscillation signature in the winter time geopotential height and temperature fields. Geophysical Research Letters, 25, 1297-1300.

Torrence, C., \& Compo, G. P. (1998). A practical guide to wavelet analysis. Bulletin of American Meteorological Society, 79, 61-78.

Tourre, Y. M., Kushnir, Y., \& White, W. B. (1999). Evolution of Interdecadal variability in sea level pressure, sea surface temperature and upper ocean temperature over the Pacific Ocean. Journal of Physical Oceanography, 29, 1528-1541.

Trenberth, K. E. (1990). Recent observed interdecadal climate changes in the Northern Hemisphere. Bulletin of American Meteorological Society, 71, 988-993.

Trenberth, K. E., \& Paolino, D. A. (1980). The Northern Hemisphere sea-level pressure data set: trends, errors, and discontinuities. Monthly Weather Review, 108, 855-872.

Trenberth, K. E., \& Hurrell, J. W. (1994). Decadal atmosphere-ocean variations in the Pacific. Climate Dynamics, 9, 303-319.

Vose, R. S., Schmoyer, R. L., Steurer, P. M., Peterson, T. C., Heim, R., Karl, T. R., \& Eischeid, J. (1992). The Global Historical Climatology Network: long-term monthly temperature, precipitation, sea level pressure, and station pressure data. ORNL/CDIAC-53, NDP-041. Carbon Dioxide Information Analysis Center, Oak Ridge National Laboratory, Oak Ridge, Tennessee.

Walsh, J. E., Chapman, W. L., \& Shy, T. L. (1996). Recent decrease of sea level pressure in the central Arctic. Journal of Climate, 9, 480-486.

Ware, D. M. (1995). A century and a half of change in the climate of the NE Pacific. Fisheries Oceanography, 4, 267-277.

Ware, D. M., \& Thomson, R. E. (2000). Interannual and multidecadal timescale climate variations in the northeast Pacific. Journal of Climate, 13, (in press).

Watanabe, M., \& Nitta, T. (1999). Decadal changes in the atmospheric circulation and associated surface climate variations in the northern hemisphere winter. Journal of Climate, 12, 494-510.

Weng, H., \& Lau, K.-M. (1994). Wavelets, period doubling, and time-frequency localization with application to organization of convection over the tropical western Pacific. Journal of Atmospheric Science, $51,2523-2541$.

Weng, W., \& Neelin, J. D. (1999). Analytical prototypes for ocean-atmosphere interaction at midlatitude. Part II: mechanisms for coupled gyre modes. Journal of Climate, 12, 2757-2774.

White, W. B., \& Cayan, D. R. (1998). Quasi-periodicity and global symmetries in interdecadal upper ocean temperature variability. Journal of Geophysical Research, 103, 21335-21354.

Yasuda, I., Sugusaki, H., Watanabe, Y., Minobe, S., \& Oo-Zeki, Y. (1999). Interdecadal variations in Japanese sardine and ocean/climate. Fishery Oceanography, 8, 18-24.

Zhang, Y., Wallace, J. M., \& Battisti, D. S. (1997). ENSO-like interdecadal variability: 1900-1993. Journal of Climate, 10, 1004-1020.

Zhang, R.-H., \& Levitus, S. (1997). Structure and cycle of decadal variability of upper ocean temperature in the North Pacific. Journal of Climate, 10, 710-727. 
Zhang, R.-H., \& Liu, Z. (1999). Decadal thermocline variability in the North Pacific Ocean: two pathways around the subtropical gyre. Journal of Climate, 12, 3273-3296.

Zhang, X., Sheng, J., \& Shabbar, A. (1998). Modes of interannual and interdecadal variability of Pacific SST. Journal of Climate, 11, 2556-2569. 